\title{
Neuromodulation approaches for the treatment of major depression \\ Challenges and recommendations from a working group meeting
}

\author{
André Russowsky Brunoni ${ }^{1}$, Chei Tung Teng ${ }^{1}$, Claudio Correa², \\ Marta Imamura3 , Joaquim P. Brasil-Neto ${ }^{4}$, Raphael Boechat ${ }^{4}$, \\ Moacyr Rosa ${ }^{5}$, Paulo Caramelli6, Roni Cohen ${ }^{7}$ Jose Alberto Del Porto ${ }^{8}$, \\ Paulo Sergio Boggio ${ }^{9}$, Felipe Fregni ${ }^{10}$
}

\begin{abstract}
The use of neuromodulation as a treatment for major depressive disorder (MDD) has recently attracted renewed interest due to development of other non-pharmacological therapies besides electroconvulsive therapy (ECT) such as transcranial magnetic stimulation (TMS), transcranial direct current stimulation (tDCS), deep brain stimulation (DBS), and vagus nerve stimulation (VNS). Method: We convened a working group of researchers to discuss the updates and key challenges of neuromodulation use for the treatment of MDD. Results: The state-of-art of neuromodulation techniques was reviewed and discussed in four sections: [1] epidemiology and pathophysiology of MDD; [2] a comprehensive overview of the neuromodulation techniques; [3] using neuromodulation techniques in MDD associated with non-psychiatric conditions; [4] the main challenges of neuromodulation research and alternatives to overcome them. Discussion: ECT is the first-line treatment for severe depression. TMS and tDCS are strategies with a relative benign profile of side effects; however, while TMS effects are comparable to antidepressant drugs for treating MDD; further research is needed to establish the role of tDCS. DBS and VNS are invasive strategies with a possible role in treatment-resistant depression. In summary, MDD is a chronic and incapacitating condition with a high prevalence; therefore clinicians should consider all the treatment options including invasive and non-invasive neuromodulation approaches. Key words: comprehensive review, major depressive disorder, ECT, TMS, clinical guidelines.
\end{abstract}

Estratégias de neuromodulação para o tratamento da depressão maior: desafios e recomendações de uma força-tarefa

\section{RESUMO}

O uso de técnicas de neuromodulação para o tratamento do transtorno depressivo maior (TDM) tem despertado um renovado interesse nos últimos anos com o desenvolvimento de outras intervenções não-farmacólogicas além da eletroconvulsoterapia (ECT), como a estimulação magnética transcraniana (EMT), a estimulação transcraniana por corrente continua (ETCC), a estimulação cerebral profunda (DBS) e a estimulação de nervo vago (VNS).

\section{Correspondence}

Felipe Fregni

Laboratory of Neuromodulation

Spaulding Rehabilitation Hospital \&

Center for Non-invasive Brain Stimulation

Beth Israel Deaconess Medical Center

Harvard Medical School

330 Brookline Ave - KS 452

Boston, MA 02215, USA

E-mail: ffregni@bidmc.harvard.edu

Received 24 September 2009 Accepted 29 September 2009
Método: Nós organizamos um grupo de trabalho com vários pesquisadores para discutir os avanços recentes e os principais desafios para o uso da neuromodulação no tratamento

'Department and Institute of Psychiatry, University of São Paulo, São Paulo SP, Brazil; ${ }^{2}$ Pain Center and Functional Neurosurgery, Hospital 9 de Julho, São Paulo SP, Brazil; ${ }^{3}$ Department of Physical Medicine and Rehabilitation, University of Paulo, São Paulo SP, Brazil; ' ${ }^{L}$ Laboratory of Neurosciences and Behavior, University of Brasília, Brasília DF, Brazil; ${ }^{5}$ Columbia University, New York, NY; ${ }^{6}$ Department of Internal Medicine (Neurology Unit), Faculty of Medicine, Federal University of Minas Gerais, Belo Horizonte MG, Brazil; ${ }^{7}$ Centro Brasileiro de Estimulação Magnética, São Paulo SP, Brazil; ${ }^{8}$ Department of Psychiatry; Federal University of São Paulo, São Paulo SP, Brazil; ${ }^{9}$ University Mackenzie, São Paulo SP, Brazil; ${ }^{10}$ Laboratory of Neuromodulation, Spaulding Rehabilitation Hospital, Harvard Medical School and Berenson-Allen Center for Noninvasive Brain Stimulation, Beth Israel Deaconess Medical Center, Harvard Medical School, Boston, MA, USA. 
do TDM. Resultados: $O$ estado-da-arte da neuromodulação foi revisado e discutido em quatro seções: [1] epidemiologia e fisiopatologia do TDM; [2] uma revisão das técnicas de neuromodulação; [3] o uso das técnicas de neuromodulação na depressão que ocorre associada ou em virtude de condições não-psiquiátricas; [4] os principais desafios da pesquisa na neuromodulação e alternativas para superá-los. Discussão: ECT é o tratamento de primeira linha para depressão grave. EMT e ETCC são estratégias com um perfil benigno de efeitos adversos; contudo, enquanto os efeitos da EMT são comparáveis ao das drogas antidepressivas para o tratamento da TDM, a eficácia da ETCC ainda precisa ser estabelecida por mais pesquisas clínicas. DBS e VNS são intervenções invasivas com um papel possível para a depressão refratária. Em resumo, TDM é uma condição crônica, incapacitante e de alta prevalência; portanto na prática clínica todas as opções de tratamento possíveis, incluindo as farmacológicas e não-farmacológicas, devem ser consideradas. Palavras-chave: artigo de revisão, transtorno depressivo maior, eletroconvulsoterapia, estimulação magnética transcraniana, recomendações para a prática clínica.

\section{INTRODUCTION}

Although the field of neuromodulation with electromagnetic stimulation is not new - dating back to the beginning of the last century with electroconvulsive therapy (ECT), followed by the invasive techniques such as deep brain stimulation in the 1960s - it recently attracted further interest due to development of novel methods of noninvasive brain stimulation such as repetitive transcranial magnetic stimulation (rTMS) and transcranial direct current stimulation (tDCS). Techniques of neuromodulation have been tested for a variety of neuropsychiatric conditions such as major depression, schizophrenia, stroke, chronic pain and Parkinson's disease. To date, the condition that was most studied on this field is major depressive disorder (MDD).

The development of alternative non-pharmacological methods of treatment for MDD is essential as this disorder has a high lifetime prevalence (between 8-16\%) ${ }^{1,2}$ and is challenging to treat as many patients fail to achieve complete remission of symptoms or have moderate to severe adverse effects with antidepressants. Therefore, updated guidelines for diagnosing and treating depression are needed.

Specific guidelines from different countries, such as Canada $^{3}$, the $\mathrm{UK}^{4}$; the $\mathrm{US}^{5}$ and $\mathrm{Brazil}^{6}$, have been published. In fact, novel treatments need to be regularly updated and incorporated to the therapeutic arsenal of the physician, such as neuromodulation therapies. We therefore convened a working group of established clinical researchers in major depression and experts in techniques of neuromodulation on August $18^{\text {th }}, 2009$ to discuss the updates and main challenges of neuromodulation use for the treatment of major depression. In this article we [I] summarize the state-of-art of neuromodulation therapies, focusing on pathophysiology, efficacy, safety and tolerability; [II] discuss opportunities of using such therapies in relatively unexplored contexts of major depression and;
Table 1. Epidemiology and prevalence of major depressive disorder (MDD) in different settings and populations.

\begin{tabular}{lc}
\hline Life-time prevalence of MDD & $6-12 \%$ \\
Annual prevalence of MDD & $3-11 \%$ \\
Relapse rate of the first depressive episode & $80 \%$ \\
Response rate after two antidepressant trials & $73 \%$ \\
Remission rate after two antidepressant trials & $47 \%$ \\
Incidence of treatment-resistant depression & $33 \%$ \\
Prevalence of pediatric and juvenile depression & $8.7 \%$ \\
Prevalence of geriatric depression & $22 \%$ \\
Prevalence of postnatal depression & $20.7 \%$ \\
Prevalence of depression in somatic diseases & \\
Prevalence of depression in Alzheimer's disease & $26 \%$ \\
Prevalence of depression in HIV/AIDS & $11 \%$ \\
Prevalence of depression in heart disease & $12 \%$ \\
Prevalence of post-stroke depression & $17 \%$ \\
Prevalence of post-MI depression & $33 \%$ \\
Prevalence of depression in diabetes & $25 \%$ \\
Prevalence of depression in cancer & $27 \%$ \\
Prevalence of depression in Parkinson's disease & $42 \%$ \\
\hline
\end{tabular}

[III] critically discuss the main challenges and future directions of brain stimulation.

\section{METHOD}

A task force meeting was set with active researchers in the fields of major depression and/or neurostimulation therapies at the Universidade Presbitariana Mackenzie, in São Paulo, Brazil, in August $18^{\text {th }}$, 2009. Participants from the working group were asked to previously submit material to the working group coordinator (FF). During the consensus meeting each participant presented his/her designated topics with input and discussion by all work- 
ing group participants. The meeting lasted 3 hours and was video-recorded. After the initial meeting, the first author (ARB) added the suggestions to the initial drafts and prepared a preliminary manuscript that was initially edited by the last author (FF) and then reviewed, edited and rectified by each co-author.

The present paper is divided in four sections: the first one overviews the epidemiology and pathophysiology of major depression; the second discusses the mechanisms of action and the clinical evidence of using each neuromodulation technique; the third section considers using neuromodulation therapies in other clinical and neurological contexts in which MDD as a comorbidity is common; finally, in the fourth section we discuss current challenges of neuromodulation research and alternatives to overcome them. One key consideration here is that the rTMS section is the longest due to the large number of studies in this area as compared to other techniques except ECT - that was less explored due to the fact that there are excellent reviews in this area and is an already established treatment for MDD with specific guidelines.

\section{Major depressive disorder Epidemiology}

MDD is a common condition that is widely frequent in population: community-baseed surveys conducted in several countries using ICD-10 criteria showed a lifetime prevalence ranging from $6-12 \%$, with an annual prevalence of $3-11 \%^{1,2,6,7}$. Current data show that MDD is an incapacitating condition: it is predicted that MDD will be the second cause of incapacitating disease in $2020^{8}$. In addition, depression is a chronic, recurrent disorder, as nearly $80 \%$ of patients relapse after the treatment of an episode ${ }^{4}$. Finally, about one third of patients have treatment-resistant depression (TRD), which is defined as the failure to achieve adequate response of symptoms after two or more antidepressant treatment trials ${ }^{9,10}$. In fact, the high prevalence of TRD, associated with failure to antidepressant response, is an important concern when managing major depression.

In this context, the National Institute of Mental Health (NIMH) sponsored the Sequenced Treatment Alternatives to Relieve Depression trial. STAR*D confirmed that the cumulative response and remission rates after two failed antidepressant treatments are $73 \%$ and $47 \%$, respectively ${ }^{11,12}$. After four failed treatments, response and remission rates decay to $19 \%$ and $13 \%{ }^{11}$. STAR*D confirmed the need for developing novel therapeutic strategies when patients fail to respond to antidepressants.

In Brazil, Andrade and colleagues ${ }^{2}$ observed a lifetime prevalence and an annual incidence of depression of $16.8 \%$ and $7.1 \%$, respectively, in a catchment area of two boroughs in São Paulo; while Almeida-Filho et al. ${ }^{13}$ observed an annual incidence of $12 \%$ in an urban sample of Bahia. In 2003, a larger survey conducted by the World Health Survey showed a 15\% of 30-day prevalence of depression $^{14}$ in Brazil. The prevalence of major depression in Brazil is likely to be similar to other countries ${ }^{2,15}$. Other studies showed, in Brazil, the prevalence of acute depressive disorder in pediatric patients, geriatric patients and in the postnatal period to be $8.7 \%, 22 \%$ and $20.7 \%$, respectively ${ }^{16-18}$.

Finally, there is a high association between MDD and other psychiatric disorders, especially anxiety disorders, impulse control disorders and substance use/abuse disorders $^{1}$, as well as with chronic medical illnesses - for instance, the prevalence of MDD in emergency departments in Latin America ranges from 23 to $35 \%{ }^{19}$; while it has been detected on average in $26 \%$ in hospitalized patients $^{20}$. These numbers confirm the need to develop novel therapeutic strategies for MDD in order to offer alternatives to patients who fail to antidepressants or those who have contraindication to these drugs.

\section{Pathophysiology}

There are several hypotheses to explain the pathophysiology of depression. It is important to review the mechanisms underlying MDD in order to understand the mechanisms of action of neuromodulation techniques.

One important and usually highly cited hypothesis of MDD is the "monoamine hypothesis". The development of antidepressant drugs in the 1960s and the following finding that such drugs had synaptic activity in circuits controlled by the neurotransmitters norepinephrine, dopamine and serotonin led to the "monoamine hypothesis" which suggests that MDD symptoms are related to low concentrations of monoamines in the synaptic cleft ${ }^{21}$. Although such view generally agrees with the pharmacological activity of antidepressant drugs (e.g. MAO inhibitors act by stopping monoamine metabolism in the pre-synaptic neuron; while serotonin selective reuptake inhibitors act by increasing serotonin concentration at the synaptic site), it is not sufficient to explain other observations - for example, the time lag of antidepressants for therapeutic action, and that symptoms of MDD do not directly relate with monoamine synaptic levels ${ }^{22}$. Other mechanisms need then to be entertained.

One interesting and increasingly discussed hypothesis is the neuroplastic hypothesis. Several animal and clinical studies showed that the Brain Derived Neurotrophic Factor (BDNF) serum levels are decreased in patients with major depression and normalized after antidepressant treatment ${ }^{23}$. BDNF expression is associated with neuronal survival and differentiation ${ }^{24}$; while lack of BDNF leads to neuronal apoptosis ${ }^{25}$. In addition, BDNF plays a key role in long-term potentiation (LTP) - a feature of neu- 
rons to facilitate the synaptic transmission in areas whose neurons are constantly demanded (on the other hand, low BDNF expression is related to Long-Term Depression (LTD) - i.e., the slowdown of neuronal activity with decreased cortical activity $)^{26}$. The neurotrophin hypothesis complements the monoamine hypothesis as synaptic activity is enhanced when monoamine levels increase - and also suggests there is a "final common pathway" of different antidepressant treatment modalities that ultimately lead to BDNF levels increasing. If the neuroplastic hypothesis is relevant to MDD, then it can be hypothesized that patients with MDD have decreased plasticity that might be accentuated in some neural circuits; therefore obstructing the creation of new synapses in areas associated with positive emotional processing.

These two previous hypotheses have lead to another one: the neural system hypothesis. The advancement of neuroimaging techniques showed that specific brain areas, such as the amygdala and the hippocampus, have a lower volume in depressed patients when compared to controls ${ }^{27,28}$. In addition, functional studies suggest a high level of activity in the ventro-medial prefrontal cortex (vmPFC) and a low level of activity in the dorso-lateral prefrontal cortex (DLPFC). It seems that patients with major depression have lower excitability in the left motor cortex $^{29}$, in the left hemisphere ${ }^{30}$ and a higher brain activity in the right cortex ${ }^{31}$. These findings suggest a "differential activity" of certain brain areas in patients with MDD, which can explain some symptoms of depression: for instance, psychomotor retardation and executive function impairment (related to the DLPFC), feelings of guilt and hopelessness (related to hippocampus and amygdala dysfunction), anhedonia (related to nucleus accumbens) and negative emotional judgment (related to left-right imbalance) $)^{32-34}$.

Another important theory lies in the influence of the hypothalamic-pituitary-adrenal (HPA) axis and its main end-product (cortisol) in cortical activity. Cortisol receptors are widely distributed in the brain, especially in the hippocampus, amygdala and hypothalamus ${ }^{35}$ - areas that are also impaired in MDD. In fact, there is convincing evidence from basic and clinical studies of overactivity of HPA axis among depressed subjects - e.g., high cortisol serum levels in depressed subjects ${ }^{36}$; and exaggerated cortisol increasing after the dexamethasone supression test $^{37}$. Along these lines, recent evidence suggests a moderate role for steroid hormones in the antidepressant efficacy of TMS; i.e., cortisol and other hormones can impair cortical activity in the brain (especially in those areas with high levels of steroid receptors) thus leading to a more severe, "endogenous" depression ${ }^{38}$.

Taken together, the integrated view of these hypotheses supports the notion that MDD is a disorder associat- ed with dysfunction in critical areas related to mood regulation. In fact, two major pathways can be determined here: the cognitive-executive pathway, in which a hypoactive DLPFC fails to regulate areas related to executive functioning; and the affective-somatic pathway, in which a hyperactive vmPFC modulates erratically areas related to negative affect and self-awareness ${ }^{39}$. The rationale in using different neurostimulation therapies is based on their mechanisms of inhibiting or enhancing activity in these pathways, as we discuss below.

\section{The neurostimulation therapies \\ Electroconvulsive therapy (ECT)}

ECT is the first and most studied brain stimulation therapy to date. In fact, Cerletti and Bini, in 1938, conducted the first descriptions of using electric stimuli to induce therapeutic seizures ${ }^{40}$. Although its mechanisms of action are still incompletely known, accumulated evidence points that its antidepressants effects are related to several mechanisms, such as restoring hemispheric balance ${ }^{41}$, increasing BDNF serum levels ${ }^{42}$, enhancing neurogenesis through a series of electrical shocks ${ }^{43}$ and, long-term up-regulation of serotonin activity and downregulation of muscarinic activity ${ }^{44}$. Nevertheless, several guidelines support the role of ECT as a first-line treatment of severe major depressive disorder, especially in psychotic and/or suicidal patients, or those with catatonia or treatment-resistant depression ${ }^{3,5,6}$.

In recent years, several systematic reviews and meta-analyses of ECT efficacy have been published ${ }^{45-47}$. The UK ECT Review Group ${ }^{45}$ reviewed the efficacy of ECT $v s$. simulated (sham) ECT ( 6 trials, 256 patients), ECT $v s$. drug therapy (18 trials, 1144 subjects), bilateral vs. unilateral (28 trials, 1408 participants), and low $v$ s. high dose ECT (7 trials, 342 patients). Compared to sham ECT, active ECT was significantly more effective, with a mean difference in endpoint Hamilton scores of 9.7 (95\% CI 5.713.5). The pooled analysis of ECT comparisons against amitriptyline, imipramine, phenelzine, or others favored ECT with a mean Hamilton difference of 5.2 (95\% CI 1.4-8.9). Bilateral ECT was more effective than unilateral (mean Hamilton reduction of 3.6 points - 95\% CI ranging between 2.2-5.2). Finally, treatment with high doses of ECT led to a greater reduction in depressive symptoms with a mean change of Hamilton scores of 4.1 (95\% CI 2.4-5.9) when compared to placebo. This meta-analysis did not identify significant differences between brief pulse vs. sinewave ECT and ECT delivered two vs. three times a week. These results were confirmed by following meta-analyses ${ }^{46,47}$.

The negative cognitive effects of ECT were explored by Sackeim et al. ${ }^{48}$ who performed an observational, naturalistic study with 751 patients who underwent ECT for 
Table 2. Summary of the neurostimulation methods.

\begin{tabular}{|c|c|c|c|c|}
\hline Method & Mechanism of action & Efficacy & Safety & Delivery method(s) \\
\hline $\begin{array}{l}\text { Electroconvulsive } \\
\text { therapy (ECT) }\end{array}$ & $\begin{array}{l}\text { Potent electric stimuli for in- } \\
\text { ducing therapeutic seizures } \\
\text { and increasing overall corti- } \\
\text { cal activity. }\end{array}$ & $\begin{array}{l}\text { Several MA showed it is } \\
\text { strongly effective for severe } \\
\text { MDD, psychotic MDD, TRD } \\
\text { and MDD with suicidal ide- } \\
\text { ation. Several MA showed it } \\
\text { is superior to simulated ECT } \\
\text { and antidepressants. }\end{array}$ & $\begin{array}{l}\text { Very low mortality rates, but } \\
\text { caution with patients with } \\
\text { cardiovascular disease. Short- } \\
\text { term side effects are head- } \\
\text { ache and myalgia. Long-term } \\
\text { cognitive impairment is pos- } \\
\text { sible, especially in subgroup } \\
\text { of patients and in some de- } \\
\text { livery methods. }\end{array}$ & $\begin{array}{l}\text { Pulse vs. Sinewave } \\
\text { Uni- vs. Bilateral } \\
\text { Bifrontal vs. Bitemporal } \\
2 \text { vs. } 3 \text { times/week }\end{array}$ \\
\hline $\begin{array}{l}\text { Repetitive } \\
\text { transcranial } \\
\text { magnetic } \\
\text { stimulation (rTMS) }\end{array}$ & $\begin{array}{l}\text { Use of electromagnetic in- } \\
\text { duction to focus induced } \\
\text { current in brain; repetitive } \\
\text { TMS modulates long-term } \\
\text { cortical excitability. }\end{array}$ & $\begin{array}{l}\text { Recent MA showed it is as } \\
\text { effective as antidepressant } \\
\text { drugs in treating MDD and } \\
\text { TRD (indirect comparison). } \\
\text { One RCT showed rTMS and } \\
\text { venlafaxine ER to have sim- } \\
\text { ilar efficacy. One subgroup } \\
\text { analysis suggests that rTMS } \\
\text { has increased efficacy in TRD } \\
\text { patients. }\end{array}$ & $\begin{array}{l}\text { Induced seizures are the } \\
\text { most severe adverse event, } \\
\text { but only } 16 \text { cases were re- } \\
\text { ported hitherto. Common } \\
\text { side effects include head- } \\
\text { ache and facial pain. No cog- } \\
\text { nitive impairment reported. }\end{array}$ & $\begin{array}{l}\text { High vs. Low frequency } \\
\text { Left vs.Right DLPFC stimulation } \\
80-120 \% \text { MT } \\
10-30 \text { sessions }\end{array}$ \\
\hline $\begin{array}{l}\text { Transcranial } \\
\text { direct current } \\
\text { stimulation (tDCS) }\end{array}$ & $\begin{array}{l}\text { Weak direct currents are ap- } \\
\text { plied to the brain via scalp } \\
\text { electrodes in a simple, pain- } \\
\text { less manner; shifting up or } \\
\text { down the cortical excitabil- } \\
\text { ity according to the current } \\
\text { polarity. }\end{array}$ & $\begin{array}{l}\text { Mixed results so far (One } \\
\text { positive and one negative } \\
\mathrm{RCT} \text {, two positive open-la- } \\
\text { bel studies). }\end{array}$ & $\begin{array}{l}\text { No serious adverse events. } \\
\text { Common side effects in- } \\
\text { clude skin irritation and itch- } \\
\text { ing sensation on the spot of } \\
\text { stimulation. }\end{array}$ & $\begin{array}{l}\text { Target area: left DLPFC } \\
\text { Reference: right DLPFC or right } \\
\text { supra-orbital area } \\
\text { 1-2 } \mathrm{mA} / 15-30 \mathrm{~min} \\
\text { 5-10 sessions }\end{array}$ \\
\hline $\begin{array}{l}\text { Deep brain } \\
\text { stimulation (DBS) }\end{array}$ & $\begin{array}{l}\text { Electrodes connected to } \\
\text { pulse generators are im- } \\
\text { planted in some brain areas, } \\
\text { the most studied is the sub- } \\
\text { genual cingulate region. }\end{array}$ & $\begin{array}{l}\text { There are only open trials } \\
\text { with small samples to date, } \\
\text { studying patients with high } \\
\text { degree of refractoriness and } \\
\text { showing response rates of } \\
50-60 \% \text {. }\end{array}$ & $\begin{array}{l}\text { Invasive brain stimulation } \\
\text { procedure with the usu- } \\
\text { al risks of a neurosurgical } \\
\text { procedure. Long-term ad- } \\
\text { verse events include trem- } \\
\text { or and transient hypomania. } \\
\text { No cognitive impairment re- } \\
\text { ported. }\end{array}$ & $\begin{array}{l}\text { Parameters of stimulation are } \\
\text { adjusted individually. }\end{array}$ \\
\hline $\begin{array}{l}\text { Vagus nerve } \\
\text { stimulation (VNS) }\end{array}$ & $\begin{array}{l}\text { Electrodes connected to } \\
\text { the left vagus nerve gener- } \\
\text { ate impulses further trans- } \\
\text { mitted to subcortical areas. }\end{array}$ & $\begin{array}{l}\text { Only one RCT, with incon- } \\
\text { clusive results. Open-label } \\
\text { studies show favorable re- } \\
\text { sults. FDA-approved for pa- } \\
\text { tients who failed +4 antide- } \\
\text { pressant treatments. }\end{array}$ & $\begin{array}{l}\text { Usual risks of a head \& neck } \\
\text { surgery. Transient hypoma- } \\
\text { nia reported. No cognitive } \\
\text { impairment reported. }\end{array}$ & $\begin{array}{l}\text { Parameters of stimulation are } \\
\text { adjusted individually. }\end{array}$ \\
\hline
\end{tabular}

MA: meta-analysis; MDD: major depressive disorder; TRD: treatment-resistant depression.

MDD. These patients went through a comprehensive neuropsychological battery at pre-ECT (baseline), after completing ECT (post-ECT) and at 6-month follow-up, which measured cognitive status, psychomotor function, attention, and several aspects of memory. They observed an important decrease in performance in almost all neuropsychological tests at post-ECT. At 6-month follow-up, patients treated with sine wave stimulation continued to have slower reaction times; while those treated with bilateral ECT had inferior performance on the global cognitive status, reaction time, Stroop effect and some memory tasks. Multi-linear regressions showed that bilater- al ECT, sine wave ECT, older age, lower premorbid cognitive function, and female gender were associated with greater cognitive effects.

In summary, despite being a very effective treatment for MDD, ECT is also associated with important cognitive deficits, especially in subgroups of patients and in specific protocols.

\section{Repetitive transcranial magnetic stimulation (rTMS) Mechanisms of action}

TMS uses the principle of electromagnetic induction to focus induced current in the brain ${ }^{49}$. When applied 
transiently, the effects last only a few minutes; however, when applied repetitively, rTMS (repetitive TMS) can modulate cortical excitability for several minutes beyond the train of stimulation ${ }^{50}$. There are two types of rTMS according to the frequency of stimulation: [1] low-frequency rTMS $(<5 \mathrm{~Hz})$ that is applied over the right DLPFC to induce a decrease in cortical excitability, and [2] high-frequency rTMS that is applied on the left DLPC to increase cortical excitability. Both approaches induce neuroplastic changes in the targeted areas - in fact, it has been suggested that high-frequency rTMS is associated with LTP and low-frequency rTMS with LTD ${ }^{51}$ : Chen and colleagues ${ }^{52}$ used a protocol ( $0.1 \mathrm{~Hz}$ for 15 minutes) similar to one that induced LTD in cortical slice preparations to stimulate the motor cortex of volunteers, showing a decrease in the motor evoked potential that persisted for several minutes, in a LTD-like phenomenon; while a TMS/EEG study showed LTP-like changes in EEG activity after high-frequency $(5 \mathrm{~Hz}) \mathrm{rTMS}^{53}$. However, there is an important variability associated with these effects and in fact subjects might respond differently to high and low-frequency rTMS according to other factors such as baseline cortical activity ${ }^{54}$.

Thus, it is hypothesized that high-frequency TMS acts by increasing activity in the left DLPFC area, thus ameliorating depression symptoms. Low-frequency rTMS, on the other hand, might act by modifying interhemispheric imbalance - i.e., as MDD might be associated with an imbalance in prefrontal cortex activity, decreasing the right DLPFC activity "releases" left DLPFC, which was being inhibited via transcallosal connections ${ }^{55}$.

\section{Efficacy of rTMS in acute MDD}

RTMS has been tested for several neurological and psychiatric conditions, but none has had the same number of studies and positive results than MDD: in fact, although the first meta-analyses published in 2003 and 2005 showed that rTMS studies were of low quality to date ${ }^{56,57}$, more recent meta-analyses published in 2007 and 2008 showed the trial design, as well as other parameters of stimulation, improved in five years, and that rTMS had the same efficacy of pharmacological drugs for MDD ${ }^{58,59}$, with also similar rates of response and remission rates for TRD (25\% and 17\%), respectively, which interestingly is similar to the STAR*D results of $19 \%$ and $13 \%{ }^{11,60}$. Currently, rTMS has been approved for use in Brazil, Canada, Israel, and some European countries and also in the US. Here it should be underscored that rTMS was only approved in the US to treat patients who failed to respond to at least one antidepressant trial as a pivotal rTMS study performed in 2007 with 301 patients with various degrees of refractoriness showed positive results only after a posthoc analysis ${ }^{61}$; however, a subsequent analysis of patients failing to at least one adequate trial found a robust posi- tive result, with an effect size of 0.83 and a drug-placebo difference of 5 points ${ }^{62}$.

To date, most rTMS trials tested its use as a combination therapy, i.e., the combination of rTMS with a pharmacological treatment - usually an antidepressant that has failed however not tapered off ${ }^{63}$. A few studies tested the use of rTMS as an accelerating therapy, i.e., the use of rTMS to hasten an antidepressant response - in this type of trial, active or sham rTMS starts simultaneously with a pharmacological treatment - 3 of 4 studies showed that the active rTMS fastened drug response. The drugs tested were venlafaxine, escitalopram or sertraline ${ }^{64}$; amitriptyline ${ }^{65}$; escitalopram ${ }^{66}$; mirtazapine or venlafaxin ${ }^{67}$ - the last trial, however, showed a negative response.

Finally, Bares and colleagues ${ }^{68}$ compared low-frequency rTMS vs. venlafaxine ER in TRD patients in a double-blind, randomized design, finding that both therapies had similar response and remission rates (rTMS: $33 \%$ and $19 \%$, venlafaxine ER: $39 \%$ and $23 \%$, respectively) as well as drop-out rates. To date, this is the first double-blinded, randomized clinical trial that directly compared rTMS against a pharmacological treatment for MDD.

\section{Efficacy of rTMS as a maintenance treatment (relapse prevention)}

Currently, there is limited data concerning using rTMS as a maintenance treatment for MDD. There are no randomized, controlled trials assessing rTMS maintenance therapy to prevent relapse as this type of trial would have some practical issues as it is not possible to randomize patients that received active treatment previously to sham treatment without compromising blinding. Therefore, the efficacy of rTMS as a maintenance treatment is better assessed through naturalistic studies. Along these lines, Fitzgerald et al. ${ }^{69}$ followed a sample of 19 patients previously treated with rTMS and observed a mean time of 10 months for relapsing, and also most of the patients were successfully treated with rTMS after relapse. Demirtas-Tatlidede et al..$^{70}$ accompanied 16 medication-free patients with TRD who responded to rTMS until relapse, when they were treated again with rTMS. Importantly, these patients continued receiving rTMS weekly or two times a week. The authors observed a medication-free period ranging from 26-43 months and that approximately $65 \%$ of patients individually sustained a clinically significant response to retreatment with rTMS. Finally, Cohen and colleagues ${ }^{71}$ followed 204 patients who remitted with rTMS assessing the time to relapse; they observed that $75 \%$ of patients had relapsed after 6 months of treatment, and a long duration of rTMS effects was negatively associated with age and positively with the number of rTMS sessions during acute treatment.

Thus, although there is little evidence on using rTMS 
Table 3. Recent meta-analyses of rTMS efficacy studies.

\begin{tabular}{|c|c|c|c|c|}
\hline Author & Year & Studies & Main results & Comments \\
\hline Martin et al..$^{56}$ & 2003 & 14 & $\begin{array}{l}\text { rTMS was more effective than sham at } 2(S M D= \\
-0.35) \text { but not at } 4 \text { weeks ( } S M D=-0.33, p=n s) \text {. }\end{array}$ & $\begin{array}{l}\text { The low quality of studies provided insufficient } \\
\text { evidence for rTMS efficacy. }\end{array}$ \\
\hline Couturier et al. ${ }^{57}$ & 2005 & 6 & $\begin{array}{l}\text { rTMS was not more effective than sham treat- } \\
\text { ment }(\mathrm{WMD}=-1.1,95 \% \mathrm{Cl}=-4.5-2.3)\end{array}$ & $\begin{array}{l}\text { Only } 6 \text { of potential } 21 \text { studies were included; } \\
\text { all studies were of low quality. }\end{array}$ \\
\hline $\begin{array}{l}\text { Herrmann and } \\
\text { Ebmeier }^{170}\end{array}$ & 2006 & 33 & $\begin{array}{l}\text { rTMS was more effective than sham, but the } \\
\text { variability was too great and no significant pre- } \\
\text { dictors were found. }\end{array}$ & $\begin{array}{l}\text { The hypotheses of underpowered studies or } \\
\text { "nonspecific" TMS effects were raised. }\end{array}$ \\
\hline Gross et al..$^{58}$ & 2007 & 5 & $\begin{array}{l}\text { rTMS was more effective than sham (SMD= } \\
-0.76 ; 9 \% \mathrm{Cl}-1.01 \text { to }-0.51)\end{array}$ & $\begin{array}{l}\text { The authors concluded rTMS design improved } \\
\text { in the past } 5 \text { years. }\end{array}$ \\
\hline Lam et al. ${ }^{60}$ & 2008 & 24 & $\begin{array}{l}\text { Response and remission rates of active } \\
\text { rTMS ( } 25 \% \text { and } 17 \%) \text { were superior to sham } \\
\text { ( } 9 \% \text { and } 6 \%) \text {. }\end{array}$ & $\begin{array}{l}\text { Only trials that included patients with treat- } \\
\text { ment-resistant depression were selected. }\end{array}$ \\
\hline Schutter et al. ${ }^{74}$ & 2009 & 30 & $\begin{array}{l}\text { rTMS was superior to sham treatment }(E S=0.39 ; \\
95 \% \mathrm{Cl} 0.25-0.54) \text { and heterogeneity was not } \\
\text { significant. }\end{array}$ & $\begin{array}{l}\text { The authors concluded the ES of rTMS is com- } \\
\text { parable to antidepressant drugs. }\end{array}$ \\
\hline
\end{tabular}

SMD: standardized mean difference; WMD: weighted mean difference; Cl: confidence interval; ES: effect size.

as a maintenance treatment for MDD, initial studies showed encouraging results - further studies should assess whether different protocols (e.g. weekly, bi-weekly, monthly rTMS applications) are better to sustain response without using antidepressant drugs. On the other hand, it is important to notice that patients who responded to a prior rTMS treatment are likely to respond again to rTMS whether they relapse.

\section{Safety and tolerability}

Loo and colleagues ${ }^{72}$ recently reviewed all published rTMS trials for side effects. They found that rTMS is a treatment virtually absent of serious side effects: in fact, only 16 patients presented seizures (the most severe side effect reported)- most of them having prior neurological disorders or using parameters outside of the recommended guidelines. In addition, they showed that rTMS did not induce cognitive impairments; in fact, some studies showed that active groups improved neuropsychological assessments. Regarding hearing loss, it has been shown that rTMS can transiently increase auditory threshold, thus wearing earplugs is recommended. Common side effects are headache that responds readily to oral analgesia and facial pain due to muscular twitches. Finally, regarding on treatment-emergent (i.e., during or after rTMS treatment) mania/hypomania, another metaanalysis showed that the risk rates are low and similar for active $(0.84 \%)$ and sham $(0.73 \%)$ groups $^{73}$. However, 9 of 13 patients who presented treatment-emergent mania/hypomania were suffering from bipolar depression.

\section{Parameters of stimulation}

Several variables should be considered when delivering rTMS treatment, such as site of stimulation, frequen- cy of trains, intensity of stimulus, frequency of sessions, and duration of treatment. Regarding left $v$ s. right stimulation, the accumulated evidence favors the former as more studies were performed stimulating the left DLP$\mathrm{FC}^{74}$; and the evidence for low-frequency right DLPFC is $\operatorname{mixed}^{75-77}$. However, low-frequency rTMS seems to be better tolerated ${ }^{78}$ and might be an interesting approach in selected cases. Considering the frequency of trains, most low-frequency protocols use $1 \mathrm{~Hz}$ or less; while high-frequency stimulation ranges from 5 to $20 \mathrm{~Hz}^{79.80}$ with more recent studies favoring the $10 \mathrm{~Hz}$-frequency ${ }^{61,67,81,82}$. Along these lines, although the intensity of stimulus (indexed to the motor threshold - MT) can vary from $80-120 \%$ MT, there is a tendency of more recent studies in using intensities $>100 \%$, when compared to the first studies that used intensities $<100 \%$ - perhaps due to safety concerns ${ }^{59}$.

rTMS is usually delivered daily in weekdays (i.e. 5 sessions per week) although other studies used different protocols such as three times a week or two times per day ${ }^{83}$. Finally, several studies have shown that a larger number of sessions is associated with a better response ${ }^{59,62}$ as well as a larger time period to relapse ${ }^{71}$. Nevertheless, this number can range from 10 to 30 sessions (i.e. 2 to 6 weeks, as sessions are not usually delivered in weekends).

Finally, one point that needs to be underscored is that parameters of stimulation have not been compared systematically and they reflect much more the personal decision of the group of researchers conducting the trial; therefore readers should consider this carefully when choosing the parameters of stimulation in clinical practice and research. Finally, individual parameters also play an important role - for instance, baseline cortical activity, medications being used by the patients. These factors can have an important interaction with the effects of rTMS. 


\section{rTMS in depressed patients with bipolar disorder}

Although the clinical manifestations of bipolar depression and MDD might be quite similar, recent evidence shows that their clinical management is different, as bipolar depression is better managed with either mood stabilizers (lithium, anticonvulsants or some atypical antipsychotics) in monotherapy or a combination of mood stabilizers and antidepressant drugs (lithium/divalproex and selective serotonin reuptake inhibitors $)^{84}$. Thus, one important question is whether rTMS for bipolar depression is as effective as for MDD. However, there are only a few studies on the topic: Nahas and colleagues ${ }^{79}$ enrolled 23 patients with bipolar depression; randomizing them to receive either high-frequency rTMS or placebo. They failed to show difference between groups. Subsequently, Dolberg and colleagues ${ }^{85}$ recruited 20 patients to receive active or sham intervention, finding mixed results - although a significant difference was observed at week-2, no difference between groups was found at the final endpoint (week-4). In 2004, Cohen et al. ${ }^{86}$ used low-frequency rTMS as an adjunctive therapy in refractory bipolar depression. In an open-label study, 22 patients received 15 sessions of rTMS - after 3 weeks, 16 showed response. Tamas and colleagues ${ }^{87}$ compared four patients on active rTMS and one on placebo, obtaining a difference between groups only at week-6. Finally, in 2009, Dell'Osso and colleagues ${ }^{88}$ performed an open-label study using low-frequency rTMS in 11 patients, showing significant reductions in all rating scales.

In conclusion, although many initial rTMS controlled trials enrolled a few depressed patients with bipolar disorder while studying major depressive disorder, the specific use of rTMS in this condition has been insufficiently explored. Thus, considering the prevalence and severity of bipolar disorder, further well-designed sham-controlled rTMS studies on this topic are needed.

\section{Cost-effectiveness}

A recent study addressed the cost-effectiveness of rTMS in major depression: using data from previous multi-center studies and of the STAR*D trial, the authors modeled the cost-effectiveness of rTMS considering different scenarios in which rTMS was combined to antidepressants after one, two or more than two drug trials failure, and comparing such association with different augmentation pharmacological strategies (antidepressant with mood stabilizers or atypical antipsychotics). Considering a base cost of US $\$ 300$ per treatment session for rTMS, the authors demonstrated that rTMS is cost-effective considering QALY criteria and might be more costeffective than certain psychopharmacological combinations (especially those combining newer antidepressants with mood stabilizers and atypical antipsychotics) ${ }^{89}$.

\section{Transcranial direct current stimulation}

Transcranial direct current stimulation (tDCS) is a renewed method of non-invasive brain modulation. It is based on a transcranial application of weak direct currents (usually up to $2 \mathrm{~mA}$ ) via scalp electrodes in a non-invasive, simple and painless manner. Other advantages are the low cost of the device and the possibility of a reliable sham control. The effects are polarity-dependent: while anodal stimulation induces an enhancement on cortical excitability, cathodal stimulation decreases it. These effects are explained as related to shifting on membrane resting potential (depolarization or hyperpolarization, respectively). Finally, the effects are also related to the stimulated area ${ }^{90}$.

The investigation on the effects of tDCS as an antidepressant therapy dates from the 1960s. However, the lack of methodological rigor on some parameters such as the target area, current strength, electrode size, reference electrode position, number of sessions, and duration of each session might explain some contradictory findings between the studies. For instance, Arfai et al. ${ }^{91}$ did not find significant effects on depression in a randomized, double-blinded, sham controlled study where tDCS $(i=0.25 \mathrm{~mA})$ was applied on frontal cortex with the reference on the thigh; on the other hand, Redfearn et $\mathrm{al}^{92}$, in an open pilot study, found a reduction of depressive symptoms after tDCS ( $\mathrm{i}=0.02$ to $0.25 \mathrm{~mA}$ ) over frontal areas with the reference electrode on the knee (for extended reviews see ${ }^{93}$ and $^{94}$ ).

This scenario began to change in the last decade with new tDCS protocols in which the parameters of stimulation were well-defined. Also, the emergence of other techniques of brain stimulation, such as TMS, allowed a better understanding of the effects of tDCS effects on cortical excitability. In the recent years, some randomized, double-blinded, sham controlled clinical trials on the effects of tDCS on depression have been conducted.

Table 4 summarizes some parameters and the observed effects of each recent protocol. As it can be observed, all recent studies targeted anodal tDCS over the left DLPFC. The only difference regarding electrodes montage is the position of cathodal electrode. Ferrucci et $\mathrm{al}^{95}$ applied this electrode over the right DLPFC whereas the other protocols used it over the contralateral supraorbital area. Besides this difference, the protocols differ with respect to number of sessions, time and intensity of stimulation current. In addition, patients of each protocol had different degrees of depression severity. Still, tDCS had antidepressant effects for patients with mild to moderate and for those with severe symptoms. In addition, it appears that the effects of repeated sessions of tDCS can prolong its therapeutic effects after the end of treatment.

A critical point to consider is the concomitant use of antidepressants - there is a difference between the stud- 


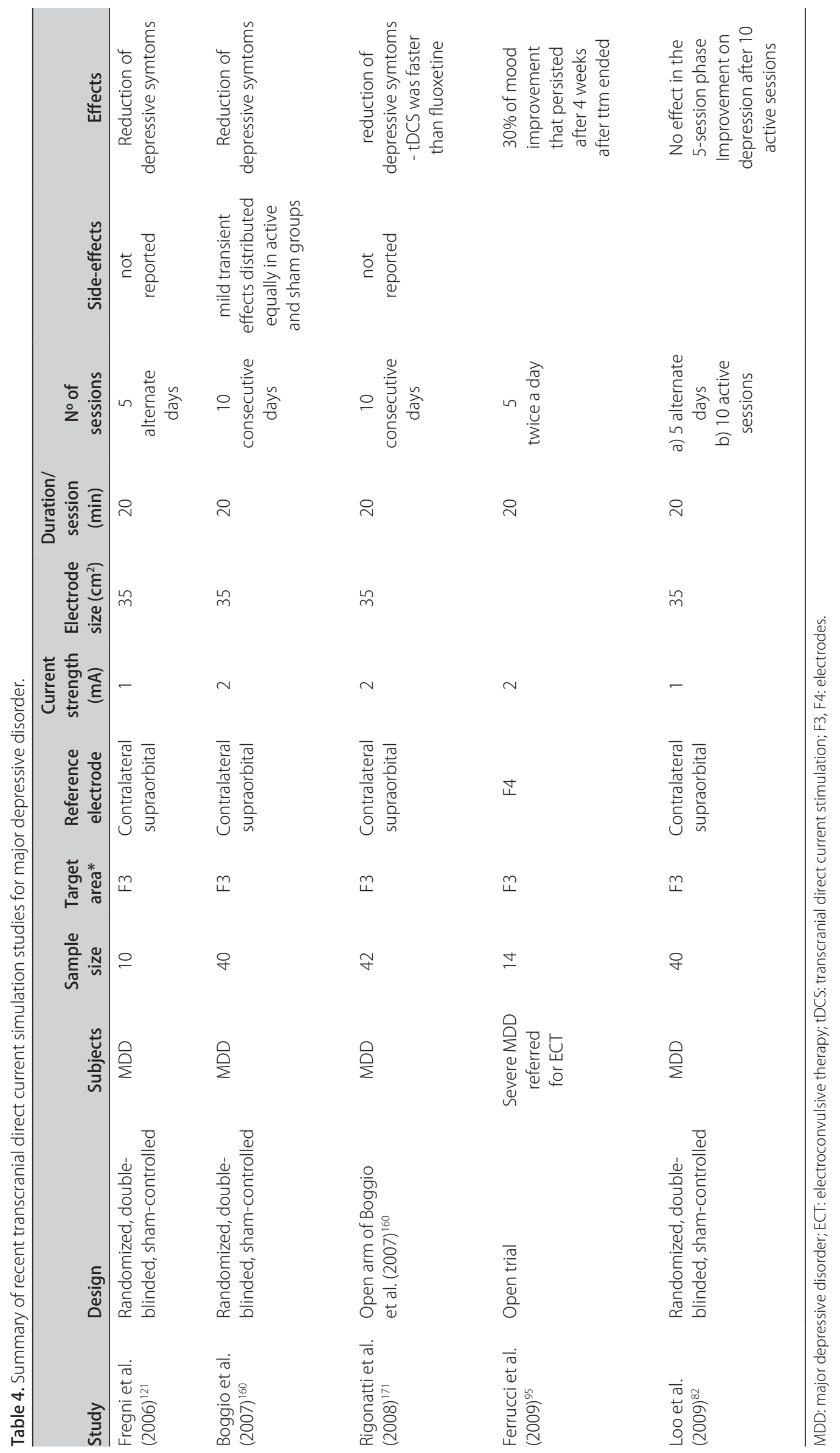


ies in this respect and this may explain differences in relation to the effect size observed in each study. For instance, Nitsche et al. ${ }^{96}$ found that citalopram increased and prolonged the facilitatory effects of anodal tDCS showing that further studies should be done investigating the association of antidepressant pharmacotherapy with tDCS.

Finally, all studies showed only mild adverse effects and those, in general, were no different from those observed in the control group.

\section{Deep brain stimulation}

Although DBS was first developed in the 1950s and was initially used for treatment of chronic pain, it has been used for MDD only recently ${ }^{97}$. When using DBS, electrodes connected to implantable pulse generators (IPG) are implanted in specific brain areas ${ }^{98-100}$. For individuals suffering from depression, electrodes may be implanted into the following regions of the brain: subthalamic nucleus, internal globus pallidus, ventral internal capsule, ventral striatum, or the subgenual cingulate ${ }^{101-104}$.

DBS is the most invasive therapy option for treatmentresistant depression. It was observed in preliminary studies that in these patients the subgenual region of the cingulate region (Broadmann area 25) is overactive-providing a rationale for implantation of deep brain stimulation devices with the aim of reducing this increased activity as stimulation in DBS has the goal to interrupt local activity.

Mayberg et al investigated the use of DBS in 6 patients with treatment-resistant depression; specifically, such patients had failed in four different medication strategies and 5 of 6 also to ECT ${ }^{104}$. After 6 months of treatment, four responded to DBS and three had full or almost full remission of depressive symptoms; while two patients had to have their DBS devices removed due to persistent infections ${ }^{104}$. This group recently published a follow-up study of these same 6 patients in which they underwent neuropsychological testing at baseline (before surgery), 3,6 , and 12-months post-surgery ${ }^{105}$. Cognitive function was evaluated and they found that DBS caused minimal to no neuropsychological adverse effects ${ }^{105}$. One interesting aspect of this study is that parameters of stimulation needed to be adjusted individually in order to provide beneficial results ${ }^{104}$.

Because the data is still scarce with this condition, several questions then need to be addressed, such as: whether DBS might be the long-term solution to patients who respond to noninvasive brain stimulation or whether it will be possible to develop portable techniques of noninvasive brain stimulation. Another important question is how to localize the optimal site of stimulation - and whether neuroimaging is enough to localize such area as it may vary across patients.

\section{Vagus nerve stimulation (VNS)}

VNS was developed relatively recently in the 1990s $\mathrm{s}^{106-108}$. It works by having an electrode attached from a pacemaker implanted on the left side of the chest to the left vagus nerve in the neck ${ }^{106,107}$. Although its mechanism of action remains elusive, it has been suggested that impulses from the vagus nerve are transmitted to the following regions: locus ceruleus, raphe nuclei, and nucleus tractus soliarious, which then project to other regions of the brain, ultimately affecting the limbic system ${ }^{109-113}$. Therefore, this may be a less focal method of electrical stimulation. In fact, the lack of focality of this technique might be associated with the limited clinical results and might favor the use of other techniques such as rTMS or DBS. In addition, it might also be used in combination with another focal method of brain stimulation. Finally, VNS is used intermittently with trains of stimulation 24 hours per day ${ }^{108,114}$.

VNS is approved in the US for treating chronic or refractory depression in patients not showing an adequate response after four antidepressant treatments. In a recent systematic review, Daban and colleagues ${ }^{115}$ could only identify one randomized clinical study, the others being open-label studies and series of cases, i.e., studies of lower methodological quality. In fact, the only blinded trial was inconclusive. Therefore, VNS may be seen as a new promising form of treatment; however the present evidence supporting its use is still limited.

\section{Other neurostimulation approaches}

Given the remarkable effects of transcranial stimulation with low-intensity constant direct current (tDCS), the use of low-intensity non-constant current (alternate current or intermittent direct current) may also prove to be an attractive option. Non-constant current can be delivered with pulses of unidirectional current in rectangular waves (intensity rapidly increased to a certain amplitude, held at the peak without change, and then interrupted by zero current) or sinusoidal waves (intensity and direction constantly varies as a function of time). In fact, non-constant current can be delivered with unidirectional current (in which pulses share the same polarity) or alternating current (in which the pulses of current alternate with opposite amplitude). Indeed, pulsed stimulation is the method used for most of brain stimulation therapies previously discussed. Of the variety of methods of low-intensity non-constant current that have been explored, here we will discuss the few specific methods of AC stimulation that have been shown to have clinical effects: cranial electrotherapy stimulation (CES), transcutaneous electrical stimulation (TCES) with Limoge's current, transcranial electrical stimulation (TES) with Lebedev's current, and transcranial alternating current stimulation (tACS). 
Cranial electrotherapy stimulation (CES) is a form of AC stimulation that involves the application of current to infra- or supra-auricular structures (e.g. the ear lobes, mastoid processes, zygomatic arches, or maxillo-occipital junction). CES is a non-standardized and often indistinct method of delivering cranial AC stimulation; indeed many studies cite the method of stimulation simply as "cranial electrotherapy stimulation" without identifying the specific site or other parameters of stimulation (e.g. duration, current density, intensity, electrode size) calling into question existing reviews of this method. Additionally, CES has been suggested to be effective in the treatment of anxiety, depression, stress, and insomnia ${ }^{116}$, and the following parameters of stimulation have been reported: frequency $(0.5 \mathrm{~Hz}$ to $167 \mathrm{kHz})$, intensity (100 uA to $4 \mathrm{~mA}$ ), duration of stimulation ( $5 \mathrm{~min}$ to up to 6 consecutive days). Of note, although alternating current is applied to the head in these circumstances, the current may or may not be delivered directly to the underlying brain structures and thus the term "transcranial" may not apply; we therefore select the term "cranial" AC stimulation to include applications of low-intensity $\mathrm{AC}$ in this context. Indeed, CES might more accurately be considered a form of peripheral nerve stimulation.

\section{Exploring brain stimulation for treating MDD in different contexts \\ Somatic diseases}

The presence of a chronic clinical diseases increases the life-long prevalence of mood disorders from $8.9 \%$ to $12.9 \%$ and the recent prevalence (last 6 months) from $5.8 \%$ to $9.4 \%$ - in fact, more severe illnesses are associated with higher rates of depressive symptoms (Table1), a condition referred as "mood disorder due to a general medical condition"117.

\section{Fibromyalgia}

Fibromyalgia - a somatic disease characterized by chronic widespread pain, allodynia in specific points, joint stiffness and fatigue - is highly associated with depression ${ }^{118}$. There are a few studies using neurostimulation techniques for treating this overlapping depressionpain condition: Carretero et al. ${ }^{119}$ reported an improvement in pain and depression after active low-frequency rTMS, but such improvement was not statistically different than sham rTMS. Passard et al. ${ }^{120}$ randomized $30 \mathrm{pa}$ tients to receive either active or sham rTMS; they were able to demonstrate a significant improvement in pain, without any positive effect on depression or anxiety. Another brain stimulation technique that has been tested for this condition was tDCS, Fregni et al. ${ }^{121}$ reported a decreased efficacy of this technique for the treatment of depressive symptoms when patients with fibromyalgia were compared to those with major depression, suggest- ing differences in the mechanisms of depression underlying these diseases. In addition, brain stimulation in these studies was aimed at decreasing pain and not depression symptoms; therefore it is unclear whether brain stimulation would have a positive clinical effect on depression in fibromyalgia.

\section{Other conditions}

Finally another issue that needs to be considered is that, in some cases, depression in some clinical conditions might be associated with changes in neural circuits that also are responsible for sustaining the clinical manifestation of disease. For instance, hypothyroidism is an example of such situation. It is well known that hypothyroidism is linked to behavioral disturbances, cognitive deficits and psychiatric illnesses ${ }^{122}$. Rizzo et al. ${ }^{123}$ studied cortical excitability to transcranial magnetic stimulation (TMS) in 10 patients with hypothyroidism, comparing them to 10 healthy volunteers. They found a few abnormalities in cortical excitability in the patients. After hormone replacement therapy with thyroid hormone over a period of 3 to 6 months, it was seen that cortical excitability parameters were back to normal. Because rTMS has been shown to induce hormonal changes, it needs to be investigated whether rTMS for depression in this condition would induce hormonal changes that might not be necessarily beneficial.

For the clinician, the cause-effect relationship between medical illness and depression is often not clear: it is not known whether depressive symptoms are a risk factor favoring the appearance of a medical ailment, or just a consequence of the latter (in fact both conditions are possible). Neurostimulation techniques will act upon specific brain areas known to be associated with the pathophysiology of depression, such as the prefrontal cortex, without acting upon areas that may be linked to the pathophysiology of the concurrent clinical illness. In this case, there is a question of whether neurostimulation would induce an improvement of depression symptoms given that mechanisms underlying MDD might be different than those of secondary depression.

\section{Neurological diseases}

Depression is a common finding in patients with neurological diseases: in fact, its prevalence is up to $50 \%$, especially in chronic conditions such as dementia, epilepsy, migraine, multiple sclerosis, Parkinson's disease and stroke. In these conditions, depressive symptoms are associated with increased burden, poor quality of life, impaired therapeutic response and, hence, to poor progno$\operatorname{sis}^{124-129}$. On the other hand, depressive symptoms associated with neurological diseases usually display a good response to pharmacological interventions, with the same drugs used in MDD, although patients may experience 
more adverse events depending on the nature of their neurological diagnosis ${ }^{130}$. Thus, new treatment approaches are still necessary in order to provide better care to this subset of patients. We discuss here the use of some of the techniques of brain stimulation for treatment of depression in neurological diseases.

\section{Post-stroke depression}

RTMS has been shown to be effective and safe in treating depression in patients with stroke. A controlled study compared sham and active rTMS on the left prefrontal cortex in patients with refractory post-stroke depression found that a series of ten sessions of active high frequency rTMS was associated with a significant reduction of depressive symptoms, with mild adverse events ${ }^{131}$.

\section{Parkinson's disease}

In MDD associated with Parkinson's disease, several open and controlled studies have been published, showing consistent improvement of depressive symptoms as well as motor symptoms after prefrontal stimulation ${ }^{132-136}$. Two randomized controlled trials showed that the efficacy of rTMS is similar to fluoxetine in patients with this condition, but with less adverse events ${ }^{133,135}$.

\section{Epilepsy}

Potential use of rTMS in epileptic patients with depression has also been suggested ${ }^{137}$, although specific studies in this indication are still lacking, but are particularly important due to safety issues as in this case lowfrequency rTMS that has a significant anti-epileptic effect can be used and therefore a combined treatment of epilepsy and depression might be possible. VNS, another related technique, has shown to be effective not only in reducing seizure frequency but also in improving depressive symptoms in epileptic patients ${ }^{138}$.

Similar opportunities might be applicable to tDCS. Because no trial with this technique has been conducted yet, this is another interesting area of future research especially due to the portability characteristics of tDCS.

\section{MDD in the rehabilitation setting}

Depressive disorders are common in the rehabilitation settings. In fact, approximately 30 to $40 \%$ of stroke survivors will experience clinically significant depression during the first year after stroke $\mathrm{e}^{139}$ and at some point following a stroke ${ }^{140,141}$. Over half of these patients will develop major or minor depression in the acute care rehabilitation settings ${ }^{142}$. In fact, depression is considered to be the strongest predictor of quality of life in this patient population ${ }^{143,144}$ and is associated with reduced rehabilitation treatment efficacy, poor functional recovery, poor social outcomes, increased cognitive impairment and increased mortality ${ }^{145}$.

Antidepressants, psychostimulants, counseling and psychotherapy are the most commonly prescribed in- terventions. However, despite showing some beneficial effects $^{146,147}$, pharmacological management of depression may be contraindicated due to their cardiovascular and anticholinergic adverse effects ${ }^{131}$. Some trials have demonstrated that selective serotonin reuptake inhibitors are no more effective than placebo in treating depression among stroke survivors ${ }^{148}$. ECT may be an alternative for refractory patients; however, caution should be exercised in stroke patients due to the risk of provoking or aggravating cognitive dysfunction.

Therefore, other safe treatment modalities are needed to effectively address this common clinical condition. RTMS may be an alternative treatment for stroke patients either with refractory depression or who are unable to use antidepressant medications. A recent study showed that ten to 15 sessions of rTMS applied on the left DLPFC at a frequency of $10 \mathrm{~Hz}$, and an intensity of $110 \%$ MT was associated with significant reduction of depressive symptoms by $30 \%$ and a remission rate of $10 \%$ as compared to placebo intervention. Mild and few adverse effects such as headache were reported ${ }^{131-149}$. Another advantage of the use of rTMS is the improvement in executive functions by rTMS ${ }^{150,151}$. Preliminary data suggests that better responses to magnetic stimulation are obtained in patients with higher frontal volumes. For patients with severe frontal atrophy, higher intensity and prolonged stimulation might be required. Finally, because of the positive effects of rTMS for motor recovery and reduction of spasticity, it is conceivable that patients might receive combined treatment for these conditions, being the parameters adjusted for either mood or motor symptoms, for instance.

\section{MDD and cognition}

In addition to the symptoms usually observed in MDD, there is also change in some cognitive domains such as verbal memory, working memory, and selective attention ${ }^{152}$. Moreover, according to depression severity and cognitive performance, some patients present a pattern of the so-called pseudodementia ${ }^{153,154}$. Also, pharmacological strategies in the management of MDD can result in negative effects on cognition - tricyclic antidepressants, for instance, have been associated with cognitive impairments in attention, memory and executive func$\operatorname{tion}^{155}$. These adverse effects indicate the need for new therapeutic strategies with fewer adverse cognitive effects and, in this scenario, neuromodulation techniques are beginning to be investigated.

Vanderhasselt et al..$^{156}$ assessed attentional control and depressive symptoms before and after rTMS over the left DLPFC. The authors observed improvement in attentional control in responders at the first rTMS session. Fitzgerald et al. ${ }^{157}$ tested the antidepressant effects of high-fre- 
quency rTMS over the left DLPFC and low-frequency over the right DLPFC. Besides the improvement of depressive symptoms in both strategies of stimulation, an improvement in immediate verbal memory and verbal fluency was also observed.

Regarding tDCS, a preliminary study by Fregni et al. ${ }^{158}$ showed that 5 days of anodal stimulation over the left DLPFC did not result in deleterious effects on functions such as memory, attention, language and executive functions. Instead, an improvement in working memory was found.

Cognitive/affective information processing is also altered in MDD. Bermpohl et al. ${ }^{159}$ investigated the effect of rTMS over the DLPFC of depressed patients in a go/ no-go task with emotional content, finding that low-frequency rTMS resulted in improved performance in the task when applied to the right DLPFC. Likewise, Boggio et al. ${ }^{160}$ investigated the effects of anodal tDCS applied over the left DLPFC of MDD patients during the same go/ no-go task, observing an improvement in performance during the tDCS session in comparison to sham or occipital stimulation.

Such observations can also be extended to depressionrelated neurological diseases, such as observed in Parkinson's disease. Fregni et al. ${ }^{161}$ found that high-frequency rTMS applied over the left DLPFC daily for ten days resulted in reduction of depressive symptoms. Boggio et al. ${ }^{162}$ found that this improvement extended to cognitive functions such as verbal fluency and executive functions. The same authors found that anodal tDCS (2 mA) applied over the left DLPFC of patients with Parkinson's disease resulted in an improvement in working memory task ${ }^{163}$.

With respect to DBS, some studies have shown that this technique is also associated with gains in memory ${ }^{164,165}$. Parameters such as amplitude and pulse width are associated with improvement in cognitive performance ${ }^{166}$. On the other hand, some authors have shown negative effects related to functions such as verbal fluency and attention ${ }^{165,167}$.

In addition, two key factors for assessing the cognitive effects of neuromodulation techniques used as tools for the treatment of depression are: 1) neural network underlying this disorder integrates structures such as prefrontal cortex, amygdala, cingulate and thalamus, and 2) cascading effects resulting from stimulation (topdown and bottom-up regulation according to the type of neuromodulation $)^{168}$.

Thus, it was observed that from the point of view of cognitive functions, neuromodulation techniques appear as promising tools associated with low cognitive adverse effects and might also improve cognitive functions. New studies are mandatory to disentangle the effects of each brain stimulation technique for each specific cognitive domain.

\section{Clinical research in brain stimulation}

To date, brain stimulation trials have produced mixed results. Despite the difficulties inherent in the technical aspects of the intervention (i.e., site of stimulation, amount of energy delivered, validation in animal studies, lack of deep understanding in its mechanisms of action), the methodology of brain stimulation trials also faces important issues that might preclude the achievement of significant results.

In a recent review, Brunoni and Fregni ${ }^{83}$ reviewed 31 brain stimulation trials published from 2002-2008 and identified some issues that could be arranged in three main topics:

[1] Issues inherent to small, exploratory studies - The small sample size of almost all trials could have produced false negative results (due to underpower) as well as false positive results (due to multiple hypothesis testing). Such caveats could be minimized in future trials by determining a priori the main hypothesis of the study and, consequently, by estimating the sample size necessary to prove the main hypothesis. For instance, the authors identified that only $20 \%$ of studies estimating sample size had negative results, while 33\% not estimating had negative results. Moreover, the authors observed the statistics of the studies are very sophisticated, which is a natural alternative to overcome the lack of power. On the other hand, the use of complex models can violate statistical assumptions and thus produce false findings.

[2] Issues inherent to MDD trials - Here the problems identified were of construct validity and reliability of the instruments used to diagnose and quantify depression. An important topic is the definition of treatment resistant depression - 30\% provided no definition, $55 \%$ defined it as when at least one antidepressant trial in adequate dose and duration failed, and 15\% required at least two failed trials. In addition, the issue of using categorical (remission) or continuous (score change) outcomes is under debate, both approaches have their pros and cons: categorical outcomes produces more clinically meaningful results but generally demands larger sample sizes; on the other hand, continuous outcomes produces more statistically meaningful results but demands smaller sample sizes.

[3] Issues specific no NIBS trials - A specific issue is blinding. In rTMS trials, the most common methods of blinding do not guarantee double-blinding, an issue that might bias results in two ways: by increasing response in the active group (by increased staff care and positive enforcement) and decreasing it in control group. Also, some authors raised the issue that angled coil - a method used in sham groups of numerous rTMS trials - might still induce cortical changes thus not being a "real" sham. On the other hand, a recent meta-analysis of sham respons- 


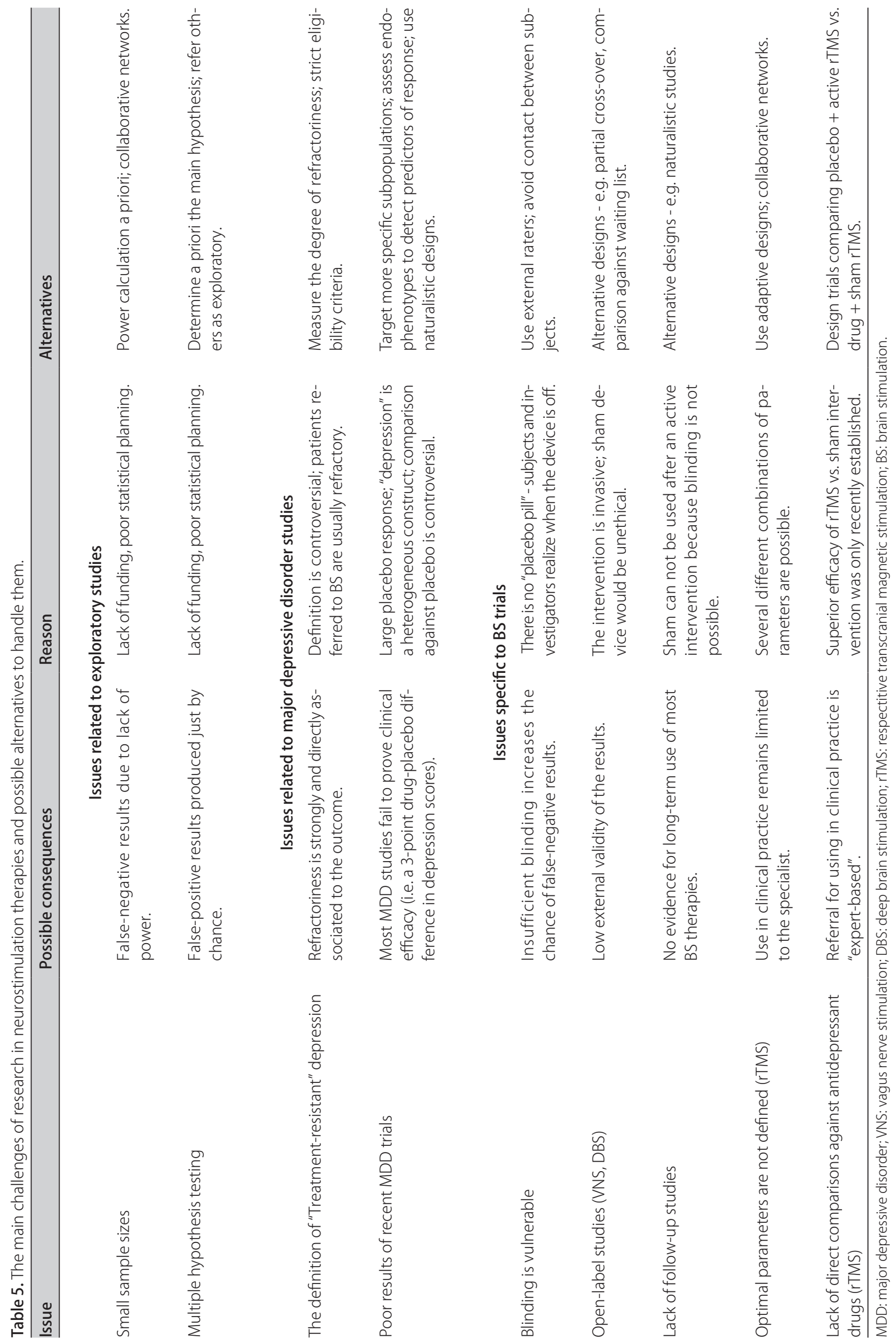


es showed angled vs. sham coils produce similar effect sizes $^{169}$. In tDCS trails, blinding vulnerability is a minor problem as; accordingly to the set of parameters specified, both groups will suffer no adverse events, thus providing a more reliable blinding. Another issue is the target sample of brain stimulation studies - focusing on treatment resistant depression per se favors smaller effect sizes.

Therefore, future directions in brain stimulation research could be: [1] to use alternative designs - after regulatory approval of some brain stimulation techniques, the use of naturalistic, follow-up studies can help to find predictors associated with better outcomes, such as age, gender, degree of refractoriness, use of concomitant medications and comorbid psychiatric diagnostics as well as endophenotypes - for instance, neuroimaging, genetic polymorphisms, BDNF baseline serum levels and neuropsychological and psychophysiological testing; [2] to recruit alternative populations - since rTMS is a safe, non-invasive technique with at least comparable effect sizes with antidepressant drugs, its use could be extended in patients not able or not ideally indicated to use medications, for example, breast-feeding women, elderly patients with polypharmacy, patients taking drugs with unfavorable pharmakocinetics (e.g. chemotherapy, immunosuppressant drugs) or even those not wanting to take pills; [3] to set a collaborative network - since most clinical studies in brain stimulation are developed in university setting with limited, public funding, the design of large trials is often unfeasible. An alternative would be to set an international collaborative network in which data are gathered from different centers - such approach could be used to do multicenter trials as well as to build a databank to perform exploratory, post-hoc analyses and identify predictors of treatment- if blood samples are collected and stored, biochemical endophenotypes could also be researched. Finally, such network would be especially important for safety issues as to identify the prevalence of side effects associated with brain stimulation; [4] to design head-to-head comparisons against pharmacological treatments - although the effect size of rTMS in recent meta-analyses is comparable to the effect size of antidepressant trials, it is not straightforward to claim such approaches have similar efficacy, as pharmacological and non-pharmacological trials are methodologically different. Therefore, direct head-to-head comparisons are necessary to evaluate this issue - along these lines, a recent trial compared low-frequency right-sided rTMS (20 sessions)+placebo $v s$. venlafaxine ER (mean dose $256 \mathrm{mg} /$ day)+sham rTMS for TRD and found both interventions to have similar efficacy in ameliorating depressive symptoms ${ }^{68}$; [5] to research optimal parameters of stimulation: the optimal number of applications (10 vs. 20 sessions), train frequency (low frequency, $5 \mathrm{~Hz}, 10 \mathrm{~Hz}, 20 \mathrm{~Hz}$ highfrequency), session parameters (low-frequency right-sided $v s$. high-frequency left-sided, concomitant application, potency in relation to motor threshold) and site of application (direct measurement for targeting DLPFC vs. neuronavegation). On the other hand, the amount of variables to combine would require several clinical trials an alternative would be to use adaptive designs, starting with several combinations and dropping weaker treatments during the trial.

\section{CONCLUSIONS}

In the current review, we convened a group of experts in the field to review and synthesize the available evidence for using neuromodulation interventions in major depressive disorder - a chronic, relapsing disorder that is associated with significant prevalence and morbidity that also accompanies many non-psychiatric conditions. In agreement with the literature, we found that ECT and rTMS are viable alternatives for treating the acute depressive episode: ECT has been widely recognized for the treatment of refractory and/or severe depression and is somewhat limited in other conditions due to adverse cognitive events and difficulty of using it in clinical practice (e.g. anesthesia, an accompanying person is needed, postECT amnesia); while rTMS might have a broader range of use as currently established by some guidelines (e.g., the FDA), however more studies are needed as the optimal parameters have not been established. DBS, VNS and tDCS are possible strategies for major depressive disorder that demand more controlled trials in order to assess their role in the realm of depressive disorders - however, while the invasiveness of DBS and VNS will naturally limit their use to the most severe spectrum of depressive disorder, the "user-friendly" approach of tDCS (i.e., low cost, absence of side effects, portable device, can be built to be operated by the patient or relative) is a promising alternative to treat a wide range of depressed patients, if such technique is proven to be effective in the near future. Along these lines, novel, non-invasive brain stimulation modalities (such as rTMS and tDCS) could be better explored when managing depressive symptoms in non-psychiatric disorders, as hazardous pharmacokinetic interactions are possible when antidepressants are associated with other drugs, and also because these novel treatments might also have positive "cognitive side effects". In summary, while to date only ECT has robust efficacy for major depressive disorder, the continuous research of novel neuromodulation techniques is showing promising results and therefore the attending physician should consider them as alternatives when treating a depressed patient. 


\section{REFERENCES}

1. Kessler RC, Berglund P, Demler O, et al. The epidemiology of major depressive disorder: results from the National Comorbidity Survey Replication (NCS-R). JAMA 2003;289:3095-3105

2. Andrade L, Caraveo-Anduaga JJ, Berglund P, et al. The epidemiology of major depressive episodes: results from the International Consortium of Psychiatric Epidemiology (ICPE) Surveys. Int J Methods Psychiatr Res 2003;12:3-21.

3. Kennedy SH, Milev R, Giacobbe P, et al. Canadian Network for Mood and Anxiety Treatments (CANMAT) clinical guidelines for the management of major depressive disorder in adults. IV. Neurostimulation therapies. J Affect Disord 2009;117:44-53.

4. Anderson IM, Ferrier IN, Baldwin RC, et al. Evidence-based guidelines for treating depressive disorders with antidepressants: a revision of the 2000 British Association for Psychopharmacology guidelines. J Psychopharmacol 2008; 22:343-396.

5. American Psychiatric Association. The practice of electroconvulsive therapy: recommendations for treatment, training and privileging (A Task Force Report of the American Psychiatric Association). $2^{\text {nd }}$ Ed. APA, 2001.

6. Fleck MP, Berlim MT, Lafer B, et al. [Review of the guidelines of the Brazilian Medical Association for the treatment of depression (Complete version)]. Rev Bras Psiquiatr 2009;31(Suppl 1):S7-S17.

7. Waraich P, Goldner EM, Somers JM, et al. Prevalence and incidence studies of mood disorders: a systematic review of the literature. Can J Psychiatry 2004; 49:124-138.

8. Murray CJ, Lopez AD. Alternative projections of mortality and disability by cause 1990-2020: Global Burden of Disease Study. Lancet 1997;349: 1498-504.

9. Nemeroff CB. Prevalence and management of treatment-resistant depression. J Clin Psychiatry 2007;68(Suppl 8):17-25.

10. Berlim MT, Turecki G. Definition, assessment, and staging of treatment-resistant refractory major depression: a review of current concepts and methods. Can J Psychiatry 2007;52:46-54.

11. Rush AJ, Trivedi MH, Wisniewski SR, et al. Acute and longer-term outcomes in depressed outpatients requiring one or several treatment steps: a STAR*D report. Am J Psychiatry 2006;163:1905-1917.

12. Trivedi MH, Fava M, Wisniewski SR, et al. Medication augmentation after the failure of SSRIs for depression. N Engl J Med 2006;354:1243-1252.

13. Almeida-Filho N, Lessa I, Magalhaes L, et al. Social inequality and depressive disorders in Bahia, Brazil: interactions of gender, ethnicity, and social class. Soc Sci Med 2004;59:1339-1353.

14. Szwarcwald CL, Viacava F. [World health survey in Brazil, 2003.]. Cad Saude Publica 2005;21(Suppl):S4-S5.

15. Simon GE, Fleck M, Lucas R, et al. Prevalence and predictors of depression treatment in an international primary care study. Am J Psychiatry 2004;161: 1626-1634.

16. Tannous L, Gigante LP, Fuchs SC, et al. Postnatal depression in Southern Brazil: prevalence and its demographic and socioeconomic determinants. BMC Psychiatry 2008;8:1

17. Blay SL, Andreoli SB, Fillenbaum GG, et al. Depression morbidity in later life: prevalence and correlates in a developing country. Am J Geriatr Psychiatry 2007; 15:790-799.

18. Fleitlich-Bilyk B, Goodman R. Prevalence of child and adolescent psychiatric disorders in southeast Brazil. J Am Acad Child Adolesc Psychiatry 2004;43: 727-734.

19. Castilla-Puentes RC, Secin R, Grau A, et al. A multicenter study of major depressive disorder among emergency department patients in Latin-American countries. Depress Anxiety 2008;25:199-204.

20. Fraguas R, Jr., Alves TC. [Depression in General Hospital: a study of 136 cases]. Rev Assoc Med Bras 2002;48:225-230.

21. Leonard BE. Evidence for a biochemical lesion in depression. J Clin Psychiatry 2000;61(Suppl 6):S12-S17.

22. Ruhe HG, Mason NS, Schene AH. Mood is indirectly related to serotonin, norepinephrine and dopamine levels in humans: a meta-analysis of monoamine depletion studies. Mol Psychiatry 2007;12:331-359.

23. Brunoni A, Lopes M, Fregni F. A systematic review and meta-analysis of clinical studies on major depression and BDNF levels: implications for the role of neuroplasticity in depression. International J Neuropsychopharmacol 2008; 11:1169-1180

24. Ventimiglia R, Mather PE, Jones BE, et al. The neurotrophins BDNF, NT-3 and NT-4/5 promote survival and morphological and biochemical differentiation of striatal neurons in vitro. Eur J Neurosci 1995;7:213-222.

25. Kuipers SD, Trentani A, Den Boer JA, et al. Molecular correlates of impaired prefrontal plasticity in response to chronic stress. J Neurochem 2003; 85: 1312-1323.

26. Gartner A, Staiger V. Neurotrophin secretion from hippocampal neurons evoked by long-term-potentiation-inducing electrical stimulation patterns. Proc Natl Acad Sci U S A 2002;99:6386-6391.

27. Hamilton JP, Siemer M, Gotlib IH. Amygdala volume in major depressive disorder: a meta-analysis of magnetic resonance imaging studies. Mol Psychiatry 2008;13:993-1000.

28. Campbell S, Macqueen $\mathrm{G}$. The role of the hippocampus in the pathophysiology of major depression. J Psychiatry Neurosci 2004;29:417-426.

29. Maeda F, Keenan JP, Pascual-Leone A. Interhemispheric asymmetry of motor cortical excitability in major depression as measured by transcranial magnetic stimulation. Br J Psychiatry 2000;177:169-173.

30. Bajwa S, Bermpohl F, Rigonatti SP, et al. Impaired interhemispheric interactions in patients with major depression. J Nerv Ment Dis 2008;196:671-677.

31. Janocha A, Pilecki W, Bolanowski M, et al. Interhemispheric cerebral asymmetry detected by VEPS in diabetic patients with recognized depression. Neuro Endocrinol Lett 2009;30:119-124.

32. Grimm S, Beck J, Schuepbach D, et al. Imbalance between left and right dorsolateral prefrontal cortex in major depression is linked to negative emotional judgment: an fMRI study in severe major depressive disorder. Biol Psychiatry 2008;63:369-376.

33. Koenigs M, Grafman J. The functional neuroanatomy of depression: distinct roles for ventromedial and dorsolateral prefrontal cortex. Behav Brain Res 2009;201:239-243.

34. Maletic V, Robinson M, Oakes T, et al. Neurobiology of depression: an integrated view of key findings. Int J Clin Pract 2007;61:2030-2040.

35. Stumpf WE, Sar M, Keefer DA. Anatomical distribution of estrogen in the central nervous system of mouse, rat, tree shrew, and squirrel monkey. Adv Biosci 1975;15:77-88.

36. Holsboer F. Corticotropin-releasing hormone modulators and depression. Curr Opin Investig Drugs 2003;4:46-50.

37. Greden JF, Kronfol Z, Gardner R, et al. Dexamethasone suppression test and selection of antidepressant medications. J Affect Disord 1981;3:389-396.

38. Schutter DJ, van Honk J. An endocrine perspective on the role of steroid hormones in the antidepressant treatment efficacy of transcranial magnetic stimulation. Psychoneuroendocrinology 2009; [epub ahead of print].

39. Stahl SM. Stahl's essential psychopharmacology: neuroscientific basis and practical implications: Cambridge University Press, 2009.

40. Bini L. Experimental researches on epileptic attacks induced by the electric current. American Journal of Psychiatry 1938;94(Suppl):S172-S174.

41. Small JG, Milstein V, Miller MJ, et al. Clinical, neuropsychological, and EEG evidence for mechanisms of action of ECT. Convuls Ther 1988;4:280-291.

42. Marano CM, Phatak P, Vemulapalli UR, et al. Increased plasma concentration of brain-derived neurotrophic factor with electroconvulsive therapy: a pilot study in patients with major depression. J Clin Psychiatry 2007;68:512-517.

43. Holtzmann J, Polosan M, Baro P, et al. [ECT: from neuronal plasticity to mechanisms underlying antidepressant medication effect]. Encephale 2007; 33: 572-578.

44. Staton RD, Enderle JD, Gerst JW. The electroencephalographic pattern during electroconvulsive therapy: V. Observations on the origins of phase III delta energy and the mechanism of action of ECT. Clin Electroencephalogr 1988; 19:176-198.

45. Group UER. Efficacy and safety of electroconvulsive therapy in depres sive disorders: a systematic review and meta-analysis. Lancet 2003;361: 799-808.

46. Pagnin D, de Queiroz V, Pini S, et al. Efficacy of ECT in depression: a meta-analytic review. J ECT 2004;20:13-20.

47. Kho KH, van Vreeswijk MF, Simpson S, et al. A meta-analysis of electroconvulsive therapy efficacy in depression. J ECT 2003;19:139-147.

48. Sackeim HA, Prudic J, Fuller R, et al. The cognitive effects of electroconvulsive therapy in community settings. Neuropsychopharmacology 2007;32: 244-254.

49. Fregni F, Pascual-Leone A. Technology insight: noninvasive brain stimulation in neurology-perspectives on the therapeutic potential of rTMS and tDCS. Nat Clin Pract Neurol 2007;3:383-393.

50. Pascual-Leone A, Tarazona F, Keenan J, et al. Transcranial magnetic stimulation and neuroplasticity. Neuropsychologia 1999;37:207-217.

51. Ilic TV, Ziemann U. Exploring motor cortical plasticity using transcranial magnetic stimulation in humans. Ann N Y Acad Sci 2005;1048:175-184.

52. Chen R, Classen J, GerloffC, et al. Depression of motor cortex excitability by lowfrequency transcranial magnetic stimulation. Neurology 1997:48:1398-1403. 
53. Esser SK, Huber R, Massimini M, et al. A direct demonstration of cortical LTP in humans: a combined TMS/EEG study. Brain Res Bull 2006;69:86-94.

54. Fregni F, Boggio PS, Valle AC, et al. Homeostatic effects of plasma valproate levels on corticospinal excitability changes induced by $1 \mathrm{~Hz}$ rTMS in patients with juvenile myoclonic epilepsy. Clin Neurophysiol 2006;117:1217-1227.

55. Steele JD, Currie J, Lawrie SM, et al. Prefrontal cortical functional abnormality in major depressive disorder: a stereotactic meta-analysis. J Affect Disord 2007;101:1-11.

56. Martin JL, Barbanoj MJ, Schlaepfer TE, et al. Repetitive transcranial magnetic stimulation for the treatment of depression. Systematic review and metaanalysis. Br J Psychiatry 2003;182:480-491.

57. Couturier JL. Efficacy of rapid-rate repetitive transcranial magnetic stimulation in the treatment of depression: a systematic review and meta-analysis. J Psychiatry Neurosci 2005;30:83-90.

58. Gross M, Nakamura L, Pascual-Leone A, et al. Has repetitive transcranial magnetic stimulation (rTMS) treatment for depression improved? A systematic review and meta-analysis comparing the recent vs. the earlier rTMS studies. Acta Psychiatr Scand 2007;116:165-173.

59. Schutter DJ. Antidepressant efficacy of high-frequency transcranial magnetic stimulation over the left dorsolateral prefrontal cortex in double-blind shamcontrolled designs: a meta-analysis. Psychol Med 2009;39:65-75

60. Lam RW, Chan P, Wilkins-Ho M, et al. Repetitive transcranial magnetic stimulation for treatment-resistant depression: a systematic review and metaanalysis. Can J Psychiatry 2008;53:621-631.

61. O'Reardon JP, Cristancho P, Pilania P, et al. Patients with a major depressive episode responding to treatment with repetitive transcranial magnetic stimulation (rTMS) are resistant to the effects of rapid tryptophan depletion. Depres Anxiety 2007;24:537-544

62. Lisanby SH, Husain MM, Rosenquist PB, et al. Daily left prefrontal repetitive transcranial magnetic stimulation in the acute treatment of major depression: clinical predictors of outcome in a multisite, randomized controlled clinical trial. Neuropsychopharmacology 2009;34:522-534

63. Brunoni AR, Fraguas R Jr., Fregni F. Pharmacological and somatic interventions for the acute depressive episode: focus on efficacy and tolerability. Ther Clin Risk Management. In press.

64. Rossini D, Magri L, Lucca A, et al. Does rTMS hasten the response to escitalopram, sertraline, or venlafaxine in patients with major depressive disorder? A double-blind, randomized, sham-controlled trial. J Clin Psychiatry 2005;66: 1569-1575.

65. Rumi DO, Gattaz WF, Rigonatti SP, et al. Transcranial magnetic stimulation accelerates the antidepressant effect of amitriptyline in severe depression: a double-blind placebo-controlled study. Biol Psychiatry 2005;57: 162-166.

66. Bretlau LG, Lunde M, Lindberg L, et al. Repetitive transcranial magnetic stimulation (rTMS) in combination with escitalopram in patients with treatmentresistant major depression: a double-blind, randomised, sham-controlled trial. Pharmacopsychiatry 2008;41:41-47.

67. Herwig U, Fallgatter AJ, Hoppner J, et al. Antidepressant effects of augmentative transcranial magnetic stimulation: randomised multicentre trial. $\mathrm{Br}$ J Psychiatry 2007;191:441-448.

68. Bares $M$, Kopecek $M$, Novak T, et al. Low frequency $(1-\mathrm{Hz})$, right prefrontal repetitive transcranial magnetic stimulation (rTMS) compared with venlafaxine ER in the treatment of resistant depression: a double-blind, single-centre, randomized study. J Affect Disord 2009;118:94-100.

69. Fitzgerald PB, Benitez J, de Castella AR, et al. Naturalistic study of the use of transcranial magnetic stimulation in the treatment of depressive relapse. Aust N Z J Psychiatry 2006;40:764-768

70. Demirtas-Tatlidede A, Mechanic-Hamilton D, Press DZ, et al. An open-label, prospective study of repetitive transcranial magnetic stimulation (rTMS) in the long-term treatment of refractory depression: reproducibility and duration of the antidepressant effect in medication-free patients. J Clin Psychiatry 2008; 69:930-934.

71. Cohen RB, Boggio PS, Fregni F. Risk factors for relapse after remission with repetitive transcranial magnetic stimulation for the treatment of depression. Depress Anxiety 2009:26:682-688.

72. Loo CK, McFarquhar TF, Mitchell PB. A review of the safety of repetitive transcranial magnetic stimulation as a clinical treatment for depression. Int J Neuropsychopharmacol 2008;11:131-147.

73. Xia G, Gajwani P, Muzina DJ, et al. Treatment-emergent mania in unipolar and bipolar depression: focus on repetitive transcranial magnetic stimulation. Int J Neuropsychopharmacol 2008;11:119-130.

74. Schutter DJ. Antidepressant efficacy of high-frequency transcranial magnetic stimulation over the left dorsolateral prefrontal cortex in double-blind shamcontrolled designs: a meta-analysis. Psychol Med 2009;39:65-75.

75. Hoppner J, Schulz M, Irmisch G, et al. Antidepressant efficacy of two different rTMS procedures. High frequency over left versus low frequency over right prefrontal cortex compared with sham stimulation. Eur Arch Psychiatry Clin Neurosci 2003:253:103-109.

76. Kauffmann CD, Cheema MA, Miller BE. Slow right prefrontal transcranial magnetic stimulation as a treatment for medication-resistant depression: a double-blind, placebo-controlled study. Depress Anxiety 2004;19:59-62.

77. Fitzgerald PB, Benitez J, de Castella A, et al. A randomized, controlled trial of sequential bilateral repetitive transcranial magnetic stimulation for treatment-resistant depression. American J Psychiatry. 2006;163:88-94.

78. Wassermann EM. Risk and safety of repetitive transcranial magnetic stimulation: report and suggested guidelines from the International Workshop on the Safety of Repetitive Transcranial Magnetic Stimulation, June 5-7, 1996. Electroencephalogr Clin Neurophysiol 1998;108:1-16

79. Nahas Z, Kozel FA, Li X, et al. Left prefrontal transcranial magnetic stimulation (TMS) treatment of depression in bipolar affective disorder: a pilot study of acute safety and efficacy. Bipolar Disord 2003;5:40-47.

80. Mosimann UP, Schmitt W, Greenberg BD, et al. Repetitive transcranial magnetic stimulation: a putative add-on treatment for major depression in elderly patients. Psychiatry Res 2004;126:123-133.

81. Mogg A, Pluck G, Eranti SV, et al. A randomized controlled trial with 4-month follow-up of adjunctive repetitive transcranial magnetic stimulation of the left prefrontal cortex for depression. Psychol Med 2008;38:323-333.

82. Loo CK, Mitchell PB, McFarquhar TF, et al. A sham-controlled trial of the efficacy and safety of twice-daily rTMS in major depression. Psychol Med 2007; 37:341-349.

83. Brunoni A, Fregni F. Improving the design of non-invasive brain stimulation trials. Int J Methods Psychiatr Res In press.

84. Yatham LN, Kennedy SH, Schaffer A, et al. Canadian Network for Mood and Anxiety Treatments (CANMAT) and International Society for Bipolar Disorders (ISBD) collaborative update of CANMAT guidelines for the management of patients with bipolar disorder: update 2009. Bipolar Disord 2009;11:225-255.

85. Dolberg OT, Dannon PN, Schreiber S, et al. Transcranial magnetic stimulation in patients with bipolar depression: a double blind, controlled study. Bipolar Disord 2002;4(Suppl 1):S94-S95.

86. Cohen RB, Carvalho M, Goncalves L, et al., editors. rTMS in treatment of resistant bipolar depression. Congresso Brasileiro de Psiquiatria. Salvador (BA), 2004.

87. Tamas RL, Menkes D, El-Mallakh RS. Stimulating research: a prospective, randomized, double-blind, sham-controlled study of slow transcranial magnetic stimulation in depressed bipolar patients. J Neuropsychiatry Clin Neurosci 2007;19:198-199.

88. Dell'Osso B, Mundo E, D'Urso N, et al. Augmentative repetitive navigated transcranial magnetic stimulation (rTMS) in drug-resistant bipolar depression. Bipolar Disord 2009;11:76-81

89. Simpson KN, Welch MJ, Kozel FA, et al. Cost-effectiveness of transcranial magnetic stimulation in the treatment of major depression: a health economics analysis. Adv Ther 2009;26:737.

90. Nitsche MA, Cohen LG, Wassermann EM, et al. Transcranial direct current stimulation: state of the art 2008 Brain Stimulat 2008;1:206-223.

91. Arfai $E$, Theano G, Montagu JD, et al. A controlled study of polarization in depression. Br J Psychiatry 1970;1 16:433-434

92. Redfearn JW, Lippold OC, Costain R. A Preliminary account of the clinical effects of polarizing the brain in certain psychiatric disorders. Br J Psychiatry 1964;110:773-785.

93. Nitsche MA, Boggio PS, Fregni F, et al. Treatment of depression with transcranial direct current stimulation (tDCS): a review. Exp Neurol 2009;219:14-19.

94. Murphy DN, Boggio P, Fregni F. Transcranial direct current stimulation as a therapeutic tool for the treatment of major depression: insights from past and recent clinical studies. Curr Opin Psychiatry 2009;22:306-311.

95. Ferrucci R, Bortolomasi M, Vergari M, et al. Transcranial direct current stimulation in severe, drug-resistant major depression. J Affect Disord 2009; 118:215-219.

96. Nitsche MA, Kuo MF, Karrasch R, et al. Serotonin affects transcranial direct current-induced neuroplasticity in humans. Biol Psychiatry 2009;66:503-508.

97. Anderson WS LF. Surgery insight: deep brain stimulation for movement disorders. Nat Clin Pract Neurol 2006;2:310-320.

98. Lujan JL, Chaturvedi A, McIntyre CC. Tracking the mechanisms of deep brain stimulation for neuropsychiatric disorders. Front Biosci 2008;13:5892-5904.

99. Benabid AL, Pollack P, Gervason C, et al. Long-term suppression of tremor by chronic stimulation of the ventral intermediate thalamic nucleus. Lancet 1991:337:403-406. 
100. Benabid AL, Pollack P, Louveau A, et al. Combined (thalamotomy and stimulation) stereotactic surgery of the VIM thalamic nucleus for bilateral Parkinson disease. Appl Neurophysiol 1987;50:344-346.

101. Greenburg BD, Malone DA, Friehs GM, et al. Three-year outcomes in deep brain stimulation for highly resistant obsessive-compulsive disorder. Neuropsychopharmacology 2006;31:2284-2393.

102. Jimenez F, Velasco F, Salin-Pascual R, et al. A patient with a resistant major depression disorder treated with deep brain stimulation in the inferior thalamic peduncle. Neurosurgery 2005;57:585-593.

103. Kosel M, Sturm V, Frick C, et al. Mood improvement after deep brain stimulation to the internal globus pallidus for tardive dyskinesia in a patient suffering from major depression. J Psychiatr Res 2007;41:801-803.

104. Mayberg HS, Lozano AM, Voon V, et al. Deep brain stimulation for treatmentresistant depression. Neuron 2005;45:651-660.

105. McNeely HE, Mayberg HS, Lozano AM, et al. Neuropsychological impact of Cg25 deep brain stimulation for treatment-resistant depression: preliminary results over 12 months. J Nerv Ment Dis 2008;196:405-410.

106. Lamberg L. Interest surging in electroconvulsive and other brain stimulation therapies. JAMA 2007;298:1147-1149.

107. Schultz D. Approval Letter: VNS therapy system - P970003s050. Rockville: Food and Drug Administration; 2005; Available from: http://www.fda.gov/ cdrh/PDF/p970003s050a.pdf.

108. Marangell LB MM, Jurdi RA, Zboyan H. Neurostimulation therapies in depression: a review of new modalities. Acta Psychiatr Scand 2007;116:174-181.

109. Foley JO DF. Quantitative studies of the vagus nerve in cat. I. The ratio of sensory and motor studies. J Comp Neurol 1937;67:49-67.

110. Van Bockstaele EJ, Peoples J, Valentino RJ, AE. Bennett Research Award. Anatomic basis for differential regulation of the rostrolateral peri-locus coeruleus region by limbic afferents. Biol Psychiatry 1999;46:1352-1363.

111. George MS, Post PR, Ketter TA, et al. Neural mechanisms of mood disorders. Curr Rev Mood Anxiety Disorders 1997;1:71-83.

112. George MS, Lisanby SH, Rush AJ, et al. Vagus nerve stimulation: a new tool for brain research and therapy. Biol Psychiatry 2000;47:287-295.

113. Drevets W. Neuroimaging studies of mood disorders. Biol Psychiatry 2000;48: 813-829.

114. Dumitriu D CK, Alterman R, Mathew S. Neurostimulatory therapeutics in management of treatment-resistant depression with focus on deep brain stimulation. Mount Sinai J of Med 2008;75:263-275.

115. Daban C, Martinez-Aran A, Cruz N, et al. Safety and efficacy of vagus nerve stimulation in treatment-resistant depression. A systematic review. J Affect Disord 2008;110:1-15

116. Kirsch DL, Smith RB. The use of cranial electrotherapy stimulation in the management of chronic pain: a review. NeuroRehabilitation. 2000;14:85-94.

117. Cassem ND, Papakostas GI, Fava M, et al. Massachusetts General Hospital, Handbook of General Hospital Psychiatry. Boston: Elsevier; 2004

118. Kanaan RA, Lepine JP, Wessely SC. The association or otherwise of the functional somatic syndromes. Psychosom Med 2007;69:855-859.

119. Carretero B, Martin MJ, Juan A, et al. Low-frequency transcranial magnetic stimulation in patients with fibromyalgia and major depression. Pain Med 2009;10:748-753

120. Passard A, Attal N, Benadhira R, et al. Effects of unilateral repetitive transcranial magnetic stimulation of the motor cortex on chronic widespread pain in fibromyalgia. Brain 2007;130:2661-2670.

121. Fregni F, Gimenes R, Valle AC, et al. A randomized, sham-controlled, proof of principle study of transcranial direct current stimulation for the treatment of pain in fibromyalgia. Arthritis Rheum 2006;54:3988-3998.

122. Kaplan MM, Young JB. Abnormal thyroid hormone deiodination in tissues of ob/ob and db/db obese mice. Endocrinology 1987;120:886-893.

123. Rizzo V, Crupi D, Bagnato S, et al. Neural response to transcranial magnetic stimulation in adult hypothyroidism and effect of replacement treatment. J Neurol Sci 2008;266:38-43.

124. Bonavita V, lavarone A, Sorrentino G. Depression in neurological diseases: a review. Arch Gerontol Geriatr 2001;7(Suppl):S49-S66.

125. Domingues RB, Costa EA, da Silva A, Jr., et al. Correlation between migraine subtypes and depression. Arq Neuropsiquiatr 2008:66:485-487.

126. Fuller-Thomson E, Brennenstuhl S. The association between depression and epilepsy in a nationally representative sample. Epilepsia 2009;50:1051-1058.

127. Mendes MF, Tilbery CP, Balsimelli S, et al. [Depression in relapsing-remitting multiple sclerosis]. Arq Neuropsiquiatr 2003;61:591-595.

128. Strober LB, Arnett PA. Assessment of depression in three medically ill, elderly populations: Alzheimer's disease, Parkinson's disease, and stroke. Clin Neuropsychol 2009;23:205-230.
129. Tatsch MF, Bottino CM, Azevedo D, et al. Neuropsychiatric symptoms in Alzheimer disease and cognitively impaired, nondemented elderly from a community-based sample in Brazil: prevalence and relationship with dementia severity. Am J Geriatr Psychiatry 2006;14:438-445.

130. Benedetti F, Bernasconi A, Pontiggia A. Depression and neurological disorders. Curr Opin Psychiatry 2006;19:14-18.

131. Jorge RE, Robinson RG, Tateno A, et al. Repetitive transcranial magnetic stimulation as treatment of poststroke depression: a preliminary study. Biol Psychiatry 2004;55:398-405.

132. Dragasevic N, Potrebic A, Damjanovic A, et al. Therapeutic efficacy of bilateral prefrontal slow repetitive transcranial magnetic stimulation in depressed patients with Parkinson's disease: an open study. Mov Disord 2002;17:528-532.

133. Cardoso EF, Fregni F, Martins Maia F, et al. rTMS treatment for depression in Parkinson's disease increases BOLD responses in the left prefrontal cortex. Int J Neuropsychopharmacol 2008;11:173-183.

134. Epstein CM, Evatt ML, Funk A, et al. An open study of repetitive transcranial magnetic stimulation in treatment-resistant depression with Parkinson's disease. Clin Neurophysiol 2007;118:2189-2194.

135. Fregni F, Santos CM, Myczkowski ML, et al. Repetitive transcranial magnetic stimulation is as effective as fluoxetine in the treatment of depression in patients with Parkinson's disease. J Neurol Neurosurg Psychiatry 2004;75:1171-1174.

136. Fregni F, Boggio PS, Bermpohl F, et al. Immediate placebo effect in Parkinson's disease: is the subjective relief accompanied by objective improvement? Eur Neurol 2006:56:222-229.

137. Fregni F, Schachter SC, Pascual-Leone A. Transcranial magnetic stimulation treatment for epilepsy: can it also improve depression and vice versa? Epilepsy Behav 2005;7:182-189.

138. Harden CL, Pulver MC, Ravdin LD, et al. A Pilot study of mood in epilepsy patients treated with vagus nerve stimulation. Epilepsy Behav 2000; 1:93-99.

139. Parikh RM, Lipsey JR, Robinson RG, et al. Two-year longitudinal study of poststroke mood disorders: dynamic changes in correlates of depression at one and two years. Stroke 1987;18:579-584.

140. Hackett ML, Yapa C, Parag V, et al. Frequency of depression after stroke: a systematic review of observational studies. Stroke 2005;36:1330-1340.

141. Paolucci S. Epidemiology and treatment of post-stroke depression. Neuropsychiatr Dis Treat 2008:4:145-154.

142. Robinson RG. Poststroke depression: prevalence, diagnosis, treatment, and disease progression. Biol Psychiatry 2003;54:376-387.

143. Kim P, Warren S, Madill H, et al. Quality of life of stroke survivors. Qual Life Res 1999;8:293-301

144. King RB. Quality of life after stroke. Stroke 1996;27:1467-1472

145. Morris PL, Robinson RG, Andrzejewski P, et al. Association of depression with 10-year poststroke mortality. Am J Psychiatry 1993;150:124-129.

146. Duncan PW, Zorowitz R, Bates B, et al. Management of adult stroke rehabilitation care: a clinical practice guideline. Stroke 2005:36:100-143.

147. Chen Y, Guo JJ. Meta-analysis of antidepressant treatment for patients with poststroke depression. Stroke 2006:37:1365-1367.

148. Robinson RG, Schultz SK, Castillo C, et al. Nortriptyline versus fluoxetine in the treatment of depression and in short-term recovery after stroke: a placebo-controlled, double-blind study. Am J Psychiatry 2000;157:351-359.

149. Jorge RE, Moser DJ, Acion L, et al. Treatment of vascular depression using repetitive transcranial magnetic stimulation. Arch Gen Psychiatry 2008; 65:268-276

150. Boroojerdi B, Phipps M, Kopylev L, et al. Enhancing analogic reasoning with rTMS over the left prefrontal cortex. Neurology 2001;56:526-528.

151. Moser DJ, Jorge RE, Manes F, et al. Improved executive functioning following repetitive transcranial magnetic stimulation. Neurology 2002:58:1288-1290.

152. Hinkelmann K, Moritz S, Botzenhardt J, et al. Cognitive impairment in major depression: association with salivary cortisol. Biol Psychiatry 2009; [Epub ahead of print].

153. Saez-Fonseca JA, Lee L, Walker Z. Long-term outcome of depressive pseudodementia in the elderly. J Affect Disord 2007;101:123-129.

154. McCall WV, Dunn AG. Cognitive deficits are associated with functional impairment in severely depressed patients. Psychiatry Res 2003;121:179-184

155. Brooks JO, Hoblyn JC. Neurocognitive costs and benefits of psychotropic medications in older adults. J Geriatr Psychiatry Neurol 2007;20:199-214

156. Vanderhasselt MA, De Raedt R, Leyman L, et al. Acute effects of repetitive transcranial magnetic stimulation on attentional control are related to antidepressant outcomes. J Psychiatry Neurosci 2009;34:119-126.

157. Fitzgerald PB, McQueen S, Herring S, et al. A study of the effectiveness of high-frequency left prefrontal cortex transcranial magnetic stimulation in major depression in patients who have not responded to right-sided stimulation. Psychiatry Res 2009;169:12-15. 
158. Fregni F, Boggio PS, Nitsche MA, et al. Treatment of major depression with transcranial direct current stimulation. Bipolar Disord 2006;8:203-204.

159. Bermpohl F, Fregni F, Boggio PS, et al. Effect of low-frequency transcranial magnetic stimulation on an affective go/no-go task in patients with major depression: role of stimulation site and depression severity. Psychiatry Res 2006;141:1-13.

160. Boggio PS, Bermpohl F, Vergara AO, et al. Go-no-go task performance improvement after anodal transcranial DC stimulation of the left dorsolateral prefrontal cortex in major depression. J Affect Disord 2007;101:91-98.

161. Fregni F, Pascual-Leone A. Transcranial magnetic stimulation for the treatment of depression in neurologic disorders. Curr Psychiatry Rep 2005;7: 381-390.

162. Boggio PS, Fregni F, Bermpohl F, et al. Effect of repetitive TMS and fluoxetine on cognitive function in patients with Parkinson's disease and concurrent depression. Mov Disord 2005;20:1178-1184

163. Boggio PS, Ferrucci R, Rigonatti SP, et al. Effects of transcranial direct current stimulation on working memory in patients with Parkinson's disease. J Neurol Sci 2006:249:31-38.

164. Hu R, Eskandar E, Williams Z. Role of deep brain stimulation in modulating memory formation and recall. Neurosurg Focus. 2009 Jul;27(1):E3.
165. Troster Al. Neuropsychology of deep brain stimulation in neurology and psychiatry. Front Biosci 2009:14:1857-1879.

166. Schoenberg MR, Mash KM, Bharucha KJ, et al. Deep brain stimulation parameters associated with neuropsychological changes in subthalamic nucleus stimulation for refractory Parkinson's disease. Stereotact Funct Neurosurg 2008:86:337-344

167. Heo JH, Lee KM, Paek SH, et al. The effects of bilateral subthalamic nucleus deep brain stimulation (STN DBS) on cognition in Parkinson disease. J Neurol Sci 2008;273:19-24.

168. Haber SN, Brucker JL. Cognitive and limbic circuits that are affected by deep brain stimulation. Front Biosci 2009;14:1823-1834.

169. Brunoni AR, Lopes M, Kaptchuk TJ, et al. Placebo response of non-pharmacological and pharmacological trials in major depression: a systematic review and meta-analysis. Plos One 2009;4:4824.

170. Herrmann LL, Ebmeier KP. Factors modifying the efficacy of transcranial magnetic stimulation in the treatment of depression: a review. The Journal of clinical psychiatry 2006;67:1870-1876.

171. Rigonatti SP, Boggio PS, Myczkowski ML, et al. Transcranial direct current stimulation and fluoxetine for the treatment of depression. Eur Psychiatry 2008;23:74-76 